\title{
Correlation of structure, function and protein dynamics in GH7 cellobiohydrolases from Trichoderma atroviride, T. reesei and $T$. harzianum
}

Anna S. Borisova ${ }^{1,2}$, Elena V. Eneyskaya², Suvamay Jana 3 , Silke F. Badino ${ }^{4}$, Jeppe Kari ${ }^{4}$, Antonella Amore ${ }^{5}$, Magnus Karlsson ${ }^{6}$, Henrik Hansson ${ }^{1}$, Mats Sandgren ${ }^{1}$, Michael E. Himmel ${ }^{5}$, Peter Westh ${ }^{4}$, Christina M. Payne $3,8^{*}$, Anna A. Kulminskaya ${ }^{2,7^{*}}$ and Jerry Ståhlberg ${ }^{1 *}$ (1)

\begin{abstract}
Background: The ascomycete fungus Trichoderma reesei is the predominant source of enzymes for industrial conversion of lignocellulose. Its glycoside hydrolase family 7 cellobiohydrolase (GH7 CBH) TreCel7A constitutes nearly half of the enzyme cocktail by weight and is the major workhorse in the cellulose hydrolysis process. The orthologs from Trichoderma atroviride (TatCel7A) and Trichoderma harzianum (ThaCel7A) show high sequence identity with TreCel7A, $\sim 80 \%$, and represent naturally evolved combinations of cellulose-binding tunnel-enclosing loop motifs, which have been suggested to influence intrinsic cellobiohydrolase properties, such as endo-initiation, processivity, and off-rate.

Results: The TatCel7A, ThaCel7A, and TreCel7A enzymes were characterized for comparison of function. The catalytic domain of TatCel7A was crystallized, and two structures were determined: without ligand and with thio-cellotriose in the active site. Initial hydrolysis of bacterial cellulose was faster with TatCel7A than either ThaCel7A or TreCel7A. In synergistic saccharification of pretreated corn stover, both TatCel7A and ThaCel7A were more efficient than TreCel7A, although TatCel7A was more sensitive to thermal inactivation. Structural analyses and molecular dynamics (MD) simulations were performed to elucidate important structure/function correlations. Moreover, reverse conservation analysis (RCA) of sequence diversity revealed divergent regions of interest located outside the cellulose-binding tunnel of Trichoderma spp. GH7 CBHs.

Conclusions: We hypothesize that the combination of loop motifs is the main determinant for the observed differences in Cel7A activity on cellulosic substrates. Fine-tuning of the loop flexibility appears to be an important evolutionary target in Trichoderma spp., a conclusion supported by the RCA data. Our results indicate that, for industrial use, it would be beneficial to combine loop motifs from TatCel7A with the thermostability features of TreCel7A. Furthermore, one region implicated in thermal unfolding is suggested as a primary target for protein engineering.
\end{abstract}

Keywords: Cellobiohydrolase, Trichoderma atroviride, Trichoderma harzianum, Trichoderma reesei, Cellulase engineering

\footnotetext{
*Correspondence: christy.payne@uky.edu; kulminskaya_aa@pnpi.nrcki.ru; jerry.stahlberg@slu.se

${ }^{1}$ Department of Molecular Sciences, Swedish University of Agricultural

Sciences, P.O. Box 7015, 75007 Uppsala, Sweden

${ }^{3}$ Department of Chemical and Materials Engineering, University

of Kentucky, 177 F. Paul Anderson Tower, Lexington, KY 40506-0046, USA

${ }^{7}$ Department of Medical Physics, Peter the Great St. Petersburg

Polytechnic University, Saint Petersburg, Russia

Full list of author information is available at the end of the article
} 


\section{Background}

Cellulolytic fungi are responsible for the majority of the degradation of terrestrial plants, which in turn accounts for most of the Earth's biomass. In many of these fungi, the major secreted enzymes are glycoside hydrolase family 7 (GH7) cellobiohydrolases (CBH) [1]. GH7 CBHs are the workhorses of cellulose degradation and, thus, play a key role in the recycling of the biosphere. Lignocellulosic biomass is also by far the most abundant renewable carbon source available to humanity for transition from fossil-based to sustainable production of fuels and chemicals. As central as these enzymes are to biomass degradation, they have become the cornerstone of modern industrial enzyme formulations for biofuel processes [2]. As such, GH7 CBHs are the target of intense structural, mechanistic, and engineering studies [3-9].

The ascomycete fungus $T$. reesei is the predominant source of enzymes for industrial lignocellulosic ethanol production, largely because of the development of hyperproducing strains capable of secreting over $50 \mathrm{~g} / \mathrm{L}$ of protein $[2,10]$. The major component, GH7 CBH from T. reesei (TreCel7A), constitutes nearly half of the total protein in the secretome [11]. TreCel7A is the most extensively studied of GH7s and serves as a model enzyme for GH7 CBHs. About one-third of the known GH7 members are bimodular, having a family 1 carbohydrate-binding module (CBM1) linked to the catalytic domain $(\mathrm{CD})$ by a glycosylated, flexible peptide comprised of about 30 amino acids [12-14]. The first crystal structure of a GH7 catalytic domain (CD) was obtained from TreCel7A in 1994 [15], and the first structure of a fungal CBM1 was determined by NMR in 1989 [16].

Structurally, GH7 proteins share a $\beta$-jelly roll fold with two $\beta$-sheets packing face-to-face into a curved $\beta$-sandwich. Loop regions extend the edges of the $\beta$-sandwich to form a 45 Å-long groove along the entire catalytic domain. CBHs within GH7 are readily distinguished because several loops are further elongated, effectively enclosing the active site in a tunnel. This enables the CBHs to act processively along a cellulose chain and cleave off numerous cellobiose units before detachment from the substrate, which is believed to be key to their efficiency on highly crystalline cellulose [7]. Although often referred to as exoglucanases, CBHs are not true exo-enzymes, in the sense that they do not seem to be exclusively restricted to chain initiation by threading of a chain end through the tunnel. Experiments with TreCel7A and Phanerochaete chrysosporium Cel7D (PchCel7D) reveal substantial ratios of endo-initiation (40-80\%; [17]), suggesting that the tunnel-enclosing loops in these enzymes are sufficiently flexible to open occasionally.

Compared to other GH families, the degree of conservation of GH7 CBHs through evolution is remarkably high. In addition to fungi, GH7 encoding genes are found in very distant branches of the eukaryotic tree of life, such as
Amoebozoa, Oomycetes, Dinoflagellates and Crustaceans. GH7 encoding genes have not been found in any prokaryote so far $[18,19]$. The sequence identity is over $40 \%$ between organisms that diverged more than 1 billion years ago, suggesting that GH7 CBHs cannot accommodate a broad sequence space for primary function [18]. Differences are primarily found in loops and surface regions distant from the active site. However, there are also small variations in the length and sequence of loop regions along the cellulose-binding path that will affect the dynamics of loop regions and the accessibility of the active site $[3,20$, 21]. These variations may in turn influence key enzymatic properties, such as processivity, product inhibition, endoinitiation and rate of substrate dissociation $[8,17]$.

Trichoderma species have attracted attention as alternative enzyme sources [22-25], among other reasons. For example, whereas $T$. reesei is a weak mycoparasite and is adapted to a saprotrophic lifestyle as a wood degrader [26], most Trichoderma spp. are described as mycoparasitic fungi and several have garnered interest as powerful biocontrol agents (BCA) against pathogenic fungi [27]. Such BCA fungi include T. harzianum and T. atroviride. These fungi have a cosmopolitan distribution and are commonly found in soil in both tropical and temperate climates. Both are considered to have a broad ecological opportunistic lifestyle, where they can live as saprotrophs of dead organic matter (plant, fungal, and animal) but also interact with plants and other fungi as mutualistic symbionts and necrotrophic mycoparasites [28]. They are widely studied for their capacity to produce antibiotics, parasitize other fungi, and control diseases caused by plant pathogenic microorganisms [29]. The cellulolytic secretomes of both $T$. harzianum and T. atroviride have higher $\beta$-glucosidase activity and are competitive with that of $T$. reesei on lignocellulose [22, 24, 30].

The GH7 CBHs of T. harzianum (ThaCel7A) and T. atroviride (TatCel7A) share the GH7_CD-linker-CBM1 bimodular organization and are very similar to each other and to TreCel7A, with $\sim 80 \%$ pairwise sequence identities. Whereas the characterization of TatCel7A has not previously been reported, the ThaCel7A enzyme has previously been isolated and characterized, and the crystal structure has been determined [21]. MD simulations demonstrated that a single mutation (Tyr371 in TreCel7A to Ala in ThaCel7A) at the tip of one loop drastically increased the flexibility of an opposing loop across the active site and, thereby, the solvent exposure of the catalytic center [21].

In contrast to distantly related homologs, $\mathrm{GH} 7 \mathrm{CBHs}$ from closely related species have obtained a limited number of evolutionary-driven mutations. The limited set of differences between the enzymes can give important insights to correlate sequence differences with enzyme function and performance. The ThaCel7A and TreCel7A enzymes can be regarded as naturally occurring variants 
of TatCel7A, particularly in terms of the combination of tunnel-enclosing loop motifs. With this view, TatCel7A is 'intermediate' between TreCel7A and ThaCel7A, combining loop motifs present in either ThaCel7A or TreCel7A. In this study, we report the biochemical and structural characterization of TatCel7A. We further compare three cellobiohydrolases, TatCel7A, ThaCel7A, and TreCel7A, side-by-side using enzyme activity and performance assays, structural analysis, MD simulation, and reversed conservation analysis (RCA) to correlate differences in sequence with differences in function.

\section{Results}

\section{Preparation of Cel7A enzymes}

The Cel7A enzymes were purified from culture filtrates of T. atroviride IOC 4503, T. harzianum IOC 3844, and T. reesei QM9414 grown in submerged culture under cellulase inducing conditions. Extracellular protein production appeared to be slightly lower for $T$. atroviride than T. harzianum, and less protein was obtained than from T. reesei. In all cases, Cel7A is the major protein (see Additional file 1: Figure S1; [11, 21]). The yield of purified enzyme per liter of culture was $70 \mathrm{mg}$ for TatCel7A and $85 \mathrm{mg}$ for ThaCel7A, compared to typical yields of 200$700 \mathrm{mg} / \mathrm{L}$ TreCel7A from T. reesei QM9414 [31]. Partial proteolysis with papain [3] could be used to remove the CBM-linker portion from the full-length enzyme and prepare isolated catalytic domains, TatCel7A_CD, ThaCel7A_CD and TreCel7A_CD.

\section{Temperature and $\mathrm{pH}$ dependence of enzyme activity and stability}

The soluble chromogenic substrate $p$-nitrophenyl- $\beta$ lactoside ( $p$ NP-Lac) was used to monitor and compare the dependence of activity and stability on temperature and $\mathrm{pH}$ for the catalytic domains of the Cel7 enzymes. The specific activity of TatCel7A_CD on $p$ NP-Lac is less than half compared to ThaCel7A_CD and TreCel7A_CD. The $\mathrm{pH}$ profiles are rather similar with a $\mathrm{pH}$ optimum around $\mathrm{pH} 4.0-4.5$, although ThaCel7A_CD seems to exhibit a slight shift in the alkaline direction and more pronounced drop in activity below pH 4 (Fig. 1a). All three enzymes are essentially inactive from $\mathrm{pH} 7$ and upward. To assess pH dependence of irreversible inactivation, the enzymes were first incubated at different $\mathrm{pHs}$ (ranging from $\mathrm{pH} 3$ to 9.5 ) for $20 \mathrm{~h}$ at $40{ }^{\circ} \mathrm{C}$ and then assayed at $\mathrm{pH} 4.5$ for residual activity on $p$ NP-Lac (Fig. 1b). All three enzymes retained full activity between $\mathrm{pH} 4$ and $\mathrm{pH} 6$ but showed a slight loss of activity at $\mathrm{pH} 3$ and substantial loss from $\mathrm{pH} 7$ and upward. The TreCel7A_CD seems to be slightly more stable at higher $\mathrm{pHs}$ than the other two enzymes. After $20 \mathrm{~h}$ incubation at $40{ }^{\circ} \mathrm{C}$ and $\mathrm{pH} 7$, the activity dropped to 80,72 , and $52 \%$ for TreCel7A_CD, ThaCel7A_CD, and TatCel7A_CD, respectively, and at $\mathrm{pH} 8$, to 43,20 , and $24 \%$, respectively. The pronounced sensitivity of ThaCel7A to $\mathrm{pH}$ above neutral was observed already during initial attempts of purification. At one stage, the protein was exposed to $\mathrm{pH}$ 8 , and the activity was lost over time. Consequently, the
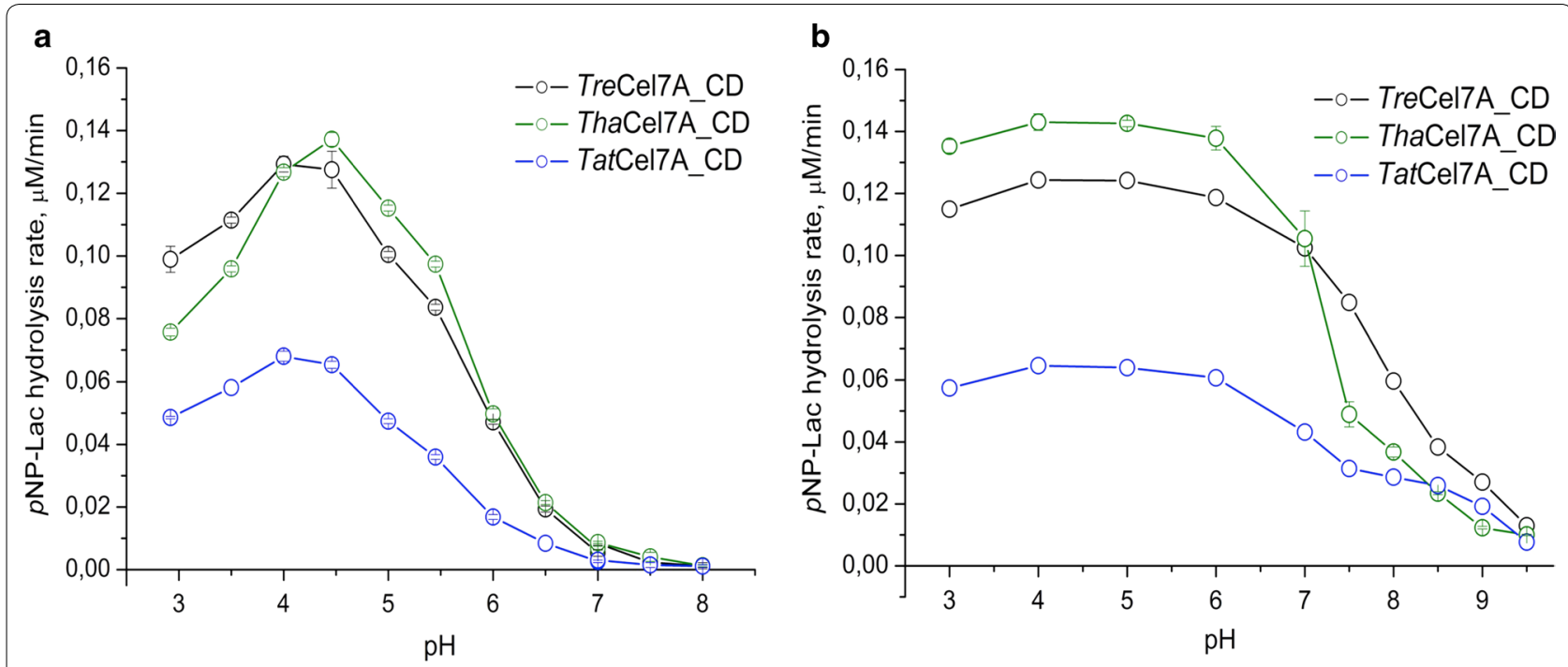

Fig. 1 pH dependence for TreCel7A_CD, ThaCel7A_CD, and TatCel7A_CD activity on pNP-Lac. a pH optimum of the activity. Hydrolysis rates were measured in reactions containing $0.15 \mu \mathrm{M}$ enzyme and $2 \mathrm{mM}$ pNP-Lac incubated $30 \mathrm{~min}$ at $30^{\circ} \mathrm{C}$ at the indicated pHs. $\mathbf{b}$ pH stability of the enzymes. After enzyme pre-incubation at different $\mathrm{pHs}$ for $20 \mathrm{~h}$ at $40^{\circ} \mathrm{C}$, residual activities were measured at $\mathrm{pH} 4.5,30{ }^{\circ} \mathrm{C}$ and $30 \mathrm{~min}$ reaction time. Error bars indicate the standard deviation of triplicate measurements 
purification procedures were adapted to avoid exposure of the Cel7A enzymes to $\mathrm{pH}>6$.

The temperature dependence plots show that TatCel7A_CD has a lower optimum temperature, $55{ }^{\circ} \mathrm{C}$, whereas the other enzymes exhibit highest activity at $60{ }^{\circ} \mathrm{C}$ (Fig. 2a). The observation that TatCel7A_CD is most temperature sensitive and TreCel7A_CD is most thermostable was confirmed by monitoring thermal inactivation over time (Fig. $2 \mathrm{~b}-\mathrm{d}$ ). At $60{ }^{\circ} \mathrm{C}$, TatCel7A_CD is inactivated after $30 \mathrm{~min}$, while ThaCel7A_CD and TreCel7A_CD retain 30 and $90 \%$ activity, respectively, after $90 \mathrm{~min}$. At $70{ }^{\circ} \mathrm{C}$, all three enzymes were inactivated within minutes.

\section{Enzyme kinetics and cellobiose inhibition}

Kinetic properties on $p$ NP-Lac and product inhibition by cellobiose was compared for TreCel7A_CD, TatCel7A_CD, and ThaCel7A_CD (Table 1). In all cases, Michaelis-Menten kinetics apply, and cellobiose acts as a competitive inhibitor (see Additional file 1: Figure S2). The $K_{\mathrm{M}}$ values are rather similar for all three, and $k_{\text {cat }} / K_{\mathrm{M}}$ is practically the same for TreCel7A_CD and ThaCel7A_ $\mathrm{CD}$. However, the catalytic rate constant $\left(k_{\mathrm{cat}}\right)$ is significantly lower for TatCel7A_CD, and its catalytic efficiency $\left(k_{\text {cat }} / K_{\mathrm{M}}\right)$ on $p$ NP-Lac is only about $25 \%$ compared to the others. All three enzymes are highly sensitive to product inhibition, but ThaCel7A_CD and TatCel7A_CD exhibit
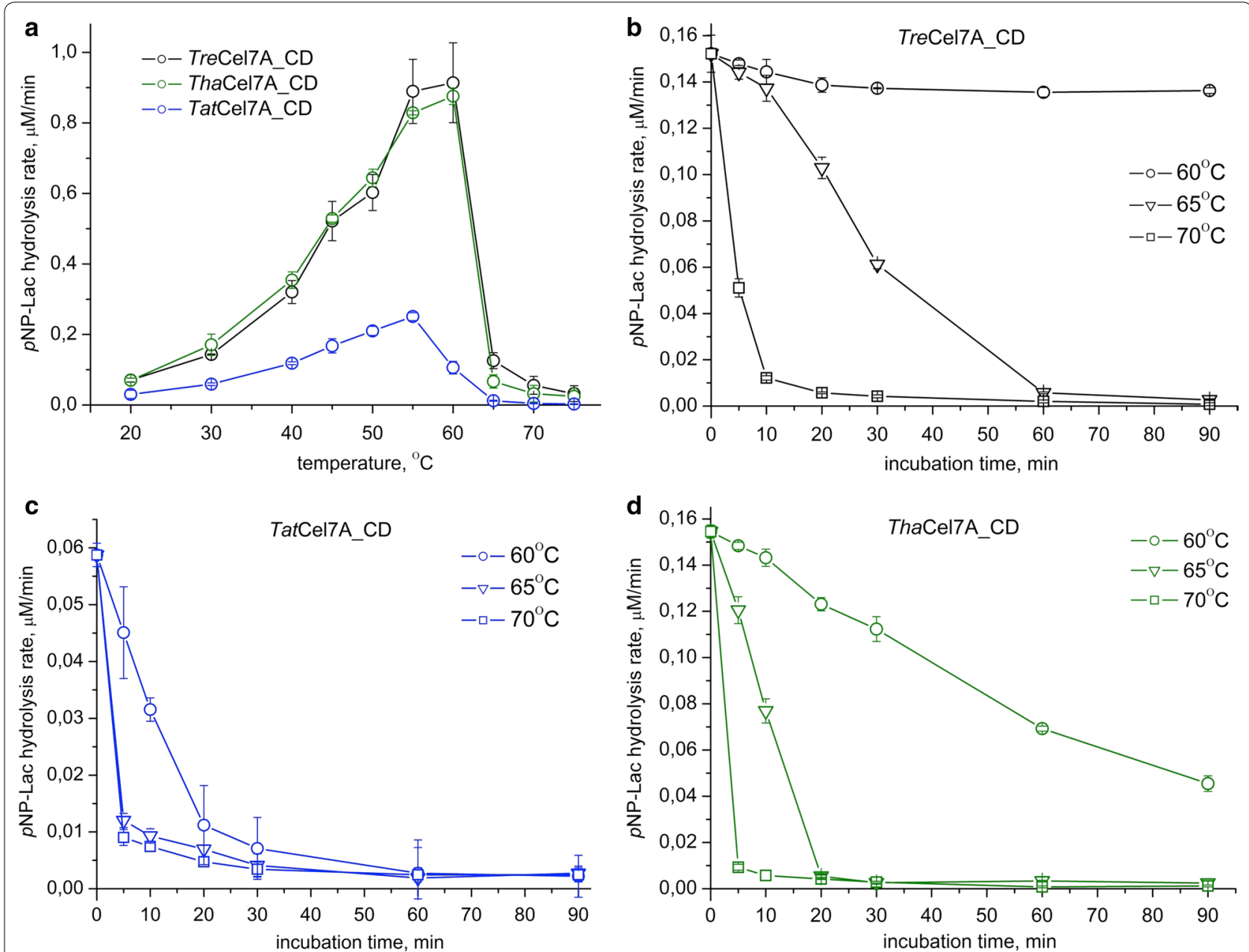

Fig. 2 Temperature dependence for TatCel7A_CD, ThaCel7A_CD, and TreCel7A_CD activity on pNP-Lac. a Temperature optimum for $1 \mathrm{~h}$ of hydrolysis at indicated temperatures. $\mathbf{b}$ Temperature stability of TreCel7A_CD. c Temperature stability of TatCel7A_CD. d Temperature stability of ThaCel7A_ $\mathrm{CD}$. For b-d the enzymes were pre-incubated at 60,65 and $70^{\circ} \mathrm{C}$ at $\mathrm{pH} 4.5$. At indicated time points, samples were cooled on ice followed by determination of residual activity at $30^{\circ} \mathrm{C}$. All reactions in $\mathbf{a}$ - $\mathbf{d}$ contained $0.15 \mu \mathrm{M}$ enzyme and $2 \mathrm{mM}$ pNP-Lac and were incubated for $1 \mathrm{~h}$ at pH 4.5 . Thereafter, the increase in pNP concentration was measured and divided by the incubation time $(60 \mathrm{~min})$ to yield the hydrolysis rates plotted on the $y$-axis. Error bars indicate the standard deviation of triplicate measurements 
Table 1 Enzyme kinetics parameters with $p$ NP-Lac as substrate and inhibition constants for cellobiose, at pH 4.5 and $30^{\circ} \mathrm{C}$

\begin{tabular}{lllll}
\hline Enzyme & $\boldsymbol{k}_{\text {cat }}\left(\mathbf{s}^{\mathbf{- 1}}\right)$ & $\boldsymbol{K}_{\mathbf{M}}(\mathbf{m M})$ & $\boldsymbol{k}_{\text {cat }} / \boldsymbol{K}_{\mathbf{M}}\left(\mathbf{s}^{-\mathbf{1}} \mathbf{M}^{-\mathbf{1}}\right)$ & $\boldsymbol{K}_{\mathbf{i}}(\boldsymbol{\mu} \mathbf{M})$ \\
\hline TreCel7A_CD & 0.057 & 0.72 & 79 & 24 \\
TatCel7A_CD & 0.019 & 1.00 & 19 & 72 \\
ThaCel7A_CD & 0.067 & 0.90 & 75 & 49 \\
\hline
\end{tabular}

$K_{\mathrm{i}}$ is the competitive inhibition constant with $100 \mu \mathrm{M}$ cellobiose in the reactions. The RMSD between calculated and experimental reaction rates was 3.4, 4.0, and 2.4\% for TreCel7A_CD, TatCel7A_CD, and ThaCel7A_CD, respectively

somewhat weaker cellobiose binding with 2 and 3 times higher $K_{\mathrm{i}}$, respectively, than TreCel7A_CD (Table 1).

\section{Initial cellulose hydrolysis}

The initial production of cellobiose from bacterial microcrystalline cellulose (BMCC) was monitored in real time using an amperometric cellobiose dehydrogenase $(\mathrm{CDH})$ enzyme biosensor [32, 33]. Figure 3 shows the progress curves for full-length TatCel7A, TreCel7A, and ThaCel7A and the TatCel7A_CD and TreCel7A_CD catalytic domains.

The experimental data in Fig. 3 were fit to a processive model $[33,34]$. The model consists of three distinct steps: enzyme-substrate association, processive catalysis, and enzyme dissociation, governed by the rate constants $k_{\text {on }}, k_{\text {cat }}$ and $k_{\text {off }}$, respectively. Further, the model

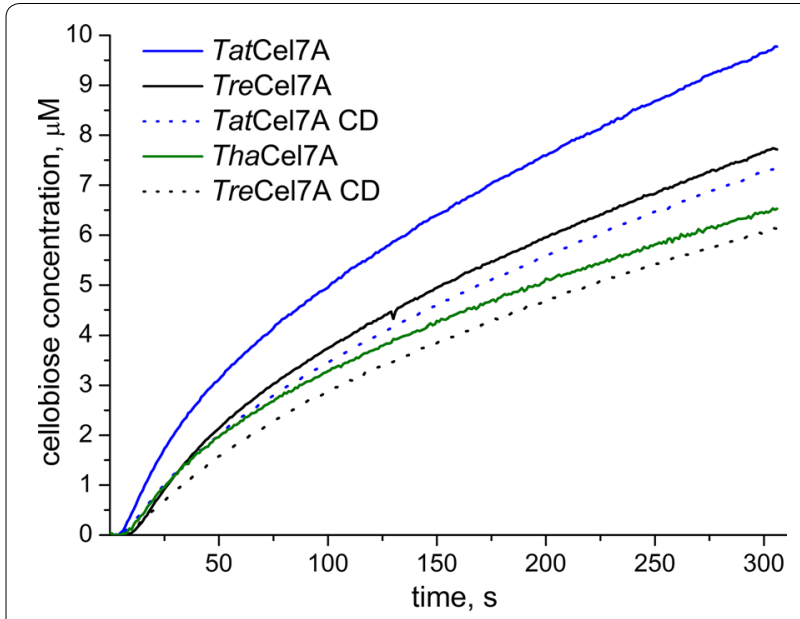

Fig. 3 Real-time progress curves of cellulose hydrolysis. Cellobiose production during initial hydrolysis of BMCC by TreCel7A, TreCel7A_ CD, TatCel7A, TatCel7A_CD, and ThaCel7A enzymes was monitored with an amperometric $\mathrm{CDH}$ enzyme biosensor. The reactions were carried out at $25^{\circ} \mathrm{C}, \mathrm{pH} 5.0$, with $3.3 \mathrm{~g} / \mathrm{L}$ of BMCC and $50 \mathrm{nM}$ enzyme. Each enzyme kinetic curve was measured in duplicate, and the average curve is plotted for each enzyme. For more details, see Additional file 1: Figure $\mathbf{S 3}$ contains an apparent processivity parameter, $n$, which represents the average number of sequential catalytic cycles. For further details, refer to Additional file 1. The kinetic parameters derived from non-linear regression are given in Table 2 . The apparent processivity of all the analyzed enzymes was similar; however, TatCel7 A exhibited 20\% higher apparent processivity than ThaCel7A and 9\% higher than TreCel7A. The catalytic domains have approximately the same processivity number as the corresponding full-length variants. The main difference in function between the full length enzymes (TreCel7A and TatCel7A) and catalytic domains (TreCel7A_CD and TatCel7A_CD) manifested in $k_{\text {on }}$, which was significantly lower for each of the catalytic domains. When comparing full-length enzymes, the kinetic parameters were similar, except for a significantly higher $k_{\text {cat }}$ for TatCel7A. Since all the enzymes were purified from the native host, a test of endoglucanase (EG) activity in the $\mathrm{CBH}$ samples was performed, using AZCL-HE-cellulose (Megazyme) as substrate. The estimated amount of EG was negligible and was not considered to affect the kinetic parameters.

\section{Enzyme performance on pretreated biomass}

The efficiency of the Cel7A enzymes in synergistic lignocellulose saccharification was assessed by performance assays on dilute acid-pretreated corn stover (PCS) as substrate. Full-length GH7 CBHs, together with a GH7 endoglucanase (Trichoderma longibrachiatum Cel7B/EG I) and a $\beta$-glucosidase, were incubated with PCS at pH 5 and $40{ }^{\circ} \mathrm{C}$, and the release of soluble sugar was followed for $96 \mathrm{~h}$ (Fig. 4). The highest conversion was obtained with TatCel7A, closely followed by ThaCel7A, both of which appeared more efficient than TreCel7A. The conversion after $47 \mathrm{~h}$ was 84,83 , and $76 \%$ for TatCel7A, ThaCel7A, and TreCel7A, respectively.

Sequence comparison of Trichoderma spp. Cel7A orthologs The protein sequences of TatCel7A, TreCel7A, and ThaCel7A all contain a signal peptide for secretion

Table 2 Kinetic parameters derived from progress curves of initial BMCC hydrolysis: association $\left(k_{\text {on }}\right)$, catalytic $\left(k_{\text {cat }}\right)$, and dissociation $\left(k_{\text {off }}\right)$ rate constants, and apparent processivity number $(n)$

\begin{tabular}{llrll}
\hline Enzyme & $\boldsymbol{k}_{\text {on }}\left(\mathbf{g}^{-\mathbf{1}} \mathbf{L} \mathbf{s}^{-\mathbf{1}}\right)$ & $\boldsymbol{k}_{\text {cat }}\left(\mathbf{s}^{\mathbf{- 1}}\right)$ & $\boldsymbol{k}_{\text {off }}\left(\mathbf{s}^{-\mathbf{1}}\right)$ & $\boldsymbol{n}$ \\
\hline TreCel7A & $0.0055 \pm 0.0002$ & $4 \pm 0.2$ & $0.0066 \pm 0.0005$ & $89 \pm 5$ \\
TreCel7A_CD & $0.0034 \pm 0.0005$ & $4.9 \pm 0.7$ & $0.0049 \pm 0.0012$ & $88 \pm 5$ \\
ThaCel7A & $0.0056 \pm 0.0002$ & $4.8 \pm 0.4$ & $0.0061 \pm 0.0002$ & $74 \pm 1$ \\
TatCel7A & $0.0071 \pm 0.0001$ & $8.3 \pm 0.3$ & $0.0071 \pm 0.0001$ & $97 \pm 1$ \\
TatCel7A_CD & $0.0044 \pm 0$ & $6.8 \pm 0.3$ & $0.0066 \pm 0.0002$ & $87 \pm 3$
\end{tabular}

These parameters were derived for the $0-200 \mathrm{~s}$ pre-steady-state time interval. The substrate load was $3.3 \mathrm{~g} / \mathrm{L}$, and the enzyme concentration was $50 \mathrm{nM}$ 


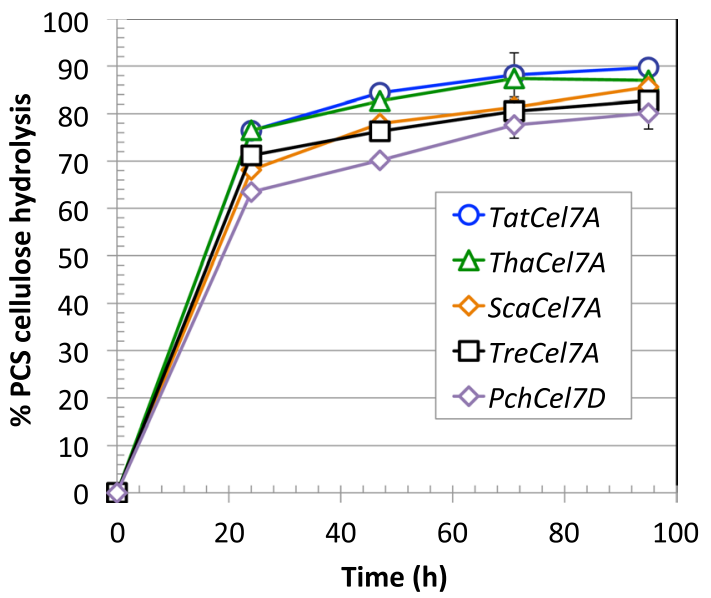

Fig. 4 Performance assay on pretreated corn stover (PCS). Synergistic conversion of PCS ( $5.0 \mathrm{~g}$ glucan/L) to soluble sugar at $40^{\circ} \mathrm{C}$ and $\mathrm{pH}$ 5.0 was monitored using full-length $\mathrm{GH} 7 \mathrm{CBH}$ enzymes $(\sim 2.5 \mu \mathrm{M})$, together with a GH7 endoglucanase and a $\beta$-glucosidase (28, 1.9, and 0.5 mg enzyme per gram glucan, respectively). In addition to the three Trichoderma CBHs, Cel7A from Scytalidium sp. (ScyCel7A; identical to the enzyme called Geotrichum candidum Cel7A in [3]) and Cel7D from Phanerochaete chrysosporium were also analyzed at the same time; the results are shown for comparison. Experiments were performed in duplicate

pathway targeting in their N-termini, followed by a GH7 catalytic domain and a C-terminal, fungal-type cellulose-binding module (CBM1). The linker region is significantly shorter in TatCel7A (22 residues), containing mostly glycine residues, whereas TreCel7A has the longest linker (30 residues) of the three enzymes (Fig. 5). A structure-based sequence alignment (excluding the signal peptide) confirms that the sequence identity is high ( 80\%; Fig. 5). All previously described loop regions are conserved in length [20], with the exception of loop A1, where three residues at the tip of the loop are missing in ThaCel7A compared to TreCel7A and TatCel7A. In addition, there are three more indels in the catalytic domains, represented by one residue deletion (between Gly298 and Ile299) and one residue insertion (Gly317) in TatCel7A, and one residue deletion in ThaCel7A (Ser24 in TatCel7A). Two $\mathrm{N}$-glycosylation sites are conserved in all three enzymes (i.e., Asn270 and Asn384 in TatCel7A).

\section{Crystal structures of TatCel7A_CD}

The TatCel7A_CD protein was successfully crystallized, and two structures were solved, one apo structure without sugars bound (APO) and one thio-cellotrioside complex (SG3). Both structures were refined at $1.7 \AA$ resolution in space group $P 21$ with two protein chains, $\mathrm{A}$ and $\mathrm{B}$, in the asymmetric unit. X-ray diffraction data and structure refinement statistics are summarized in Table 3.
The APO structure was obtained from co-crystallization of TatCel7A_CD with thio-linked cellobiose, but no cellobiose is seen in the structure. In the SG3 structure, from co-crystallization with thio-linked cellotriose, there are two cellotrioside molecules bound to each protein chain, in subsites $-6 /-5 /-4$ and $+1 /+2 /+3$, respectively (Figs. 6, 7). In both protein chains of both structures, all amino acids from 1 to 430 of TatCel7A_CD could be included in the structure model. The N-terminal glutamine residue is cyclized to pyroglutamate (PCA1), the $\mathrm{C}$-terminal residue is Gly430, and all the 20 cysteines form disulfide bridges. $\mathrm{N}$-glycosylation is visible at one site, with one GlcNAc residue attached to Asn270. In the APO structure, there is distinct density for a BisTris molecule bound to the catalytic residues, Glu212, Asp214, and Glu271, at the catalytic center of the active site, whereas glycerol is found in a similar position in the SG3 structure.

The position and conformation of the thio-cellotrioside ligands in the SG3 structure are well defined by the electron density, as shown in Fig. 7. For the ligand in the $-6 /-5 /-4$ position at the tunnel entrance, all glucose residues adopt the ${ }^{4} C_{1}$ chair conformation, but the $\mathrm{C} 1$ hydroxyl at the reducing end in subsite -4 is predominantly in the $\alpha$-position, with very weak density for a $\beta$-hydroxyl. Interestingly, the sugar ring at each site is flipped upside down compared to the orientation in the Michaelis complex of TreCel7A (Fig. 7a). The binding may represent a sliding intermediate during processive cellulose hydrolysis. The flipped orientation could also be a consequence of the slight difference in geometry of the thio-ether linkage compared to that of a standard $O$-glycosidic bond. On the other hand, another Cel7A structure (4ZZT) shows two thio-cellotrioside molecules bound in subsites $-4 /-3 /-2$ and $-1 /+1 /+2$ in the normal orientation (Fig. 8). The other thio-cellotrioside molecule in the SG3 structure, at $+1 /+2 /+3$, is in register and aligns well with the glycan binding at the product sites of the TreCel7A Michaelis complex. The +1 and +2 glucosides are in ${ }^{4} C_{1}$ chair conformations, whereas the +3 unit at the reducing end adopts a ${ }^{1} S_{3}$ skew conformation, again with $\alpha$-hydroxyl predominance at the anomeric carbon. The sugar ring distortion is not induced by crystal contacts, since there are no interactions with any neighbor protein in this region.

Overall, the TatCel7A_CD structures are very similar (0.18 $\AA$ root mean square deviation, RMSD), although there is a general 'tightening' of the protein around the active site in SG3 compared to APO, which is most pronounced at the A4-loop near the product sites (Fig. 9). The fold is very similar to that of TreCel7A_CD and ThaCel7A_CD (RMSD 0.54 and $0.44 \AA$, respectively), as 


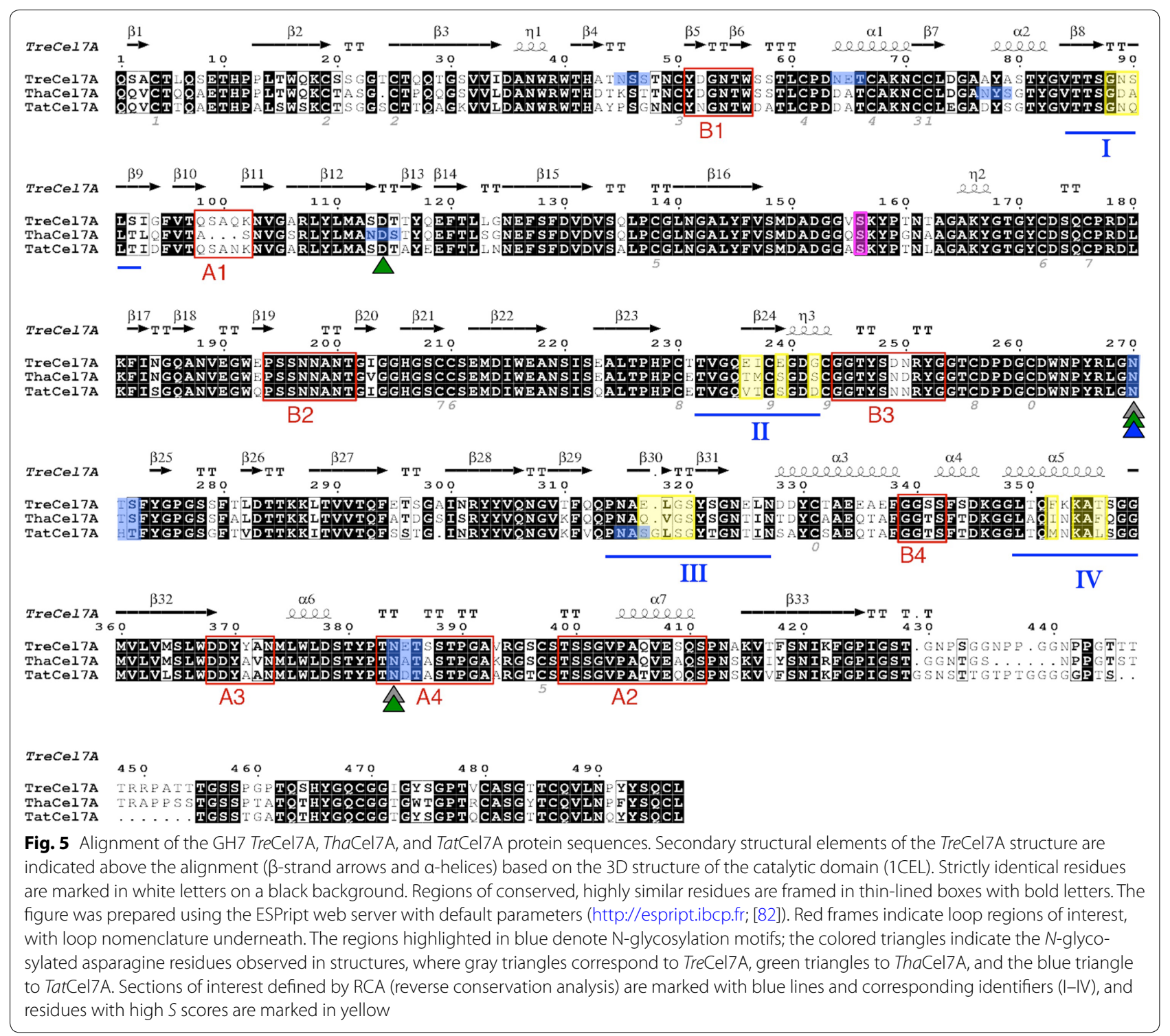

expected from the high sequence identity (80 and $82 \%$, respectively).

The lining of the cellulose-binding path is identical in the three enzymes except at two locations, loop A1 at the entrance to the tunnel and loop A3 near the catalytic center (Fig. 6). In loop A1, Glu101 in TreCel7A binds the 6-hydroxyl of the glucose unit in subsite -6 . This residue is replaced by a shorter sidechain, Asn101, in TatCel7A. Nevertheless, Asn101 may still bind to the cellulose chain but probably results in a weaker interaction. In ThaCel7A, a corresponding interaction is completely absent, since the tip of the A1 loop is three residues shorter (99-101 in TatCel7A and TreCel7A) [21]. The shorter A1 loop does not reach over subsite - 6, making the entrance to the tunnel more open in ThaCel7A
(Fig. 6). At the second location, loop A3, Tyr371 in TreCel7A interacts with Tyr247 at the tip of the opposing B3 loop. Tyr371 is replaced by an alanine in both TatCel7A and ThaCel7A, and there are no direct interactions between loops A3 and B3 across the tunnel. Also, loop B3 has moved outwards in TatCel7A and ThaCel7A compared to the TreCel7A structure (5.5 $\AA$ distance between Tyr247 OH of TatCel7A and TreCel7A). At the next position in loop A3, Ala372 of TatCel7A and TreCel7A is replaced by a valine in ThaCel7A, which appears to influence the dynamics of the adjacent A4 loop near the product site.

The overall backbone structures of the three enzymes are very similar, apart from small deviations in loops and turns at the surface of the protein. However, there is one 
Table 3 X-ray diffraction data and refinement statistics for the TatCel7A_CD structures

\begin{tabular}{|c|c|c|}
\hline & Apo structure (APO) & Thio-cellotriose complex (SG3) \\
\hline \multicolumn{3}{|l|}{ Data collection } \\
\hline PDB accession no. & $5 \mathrm{O} 5 \mathrm{D}$ & 5059 \\
\hline Beam line & 1911-3, MAX-lab & ID23-1, ESRF \\
\hline $\begin{array}{l}\text { Space group } \\
\text { Cell dimensions }\end{array}$ & P21 & P21 \\
\hline$a, b, c(\AA)$ & $56.17,71.67,104.22$ & $55.85,71.34,102.91$ \\
\hline Wavelength $(\AA ̊)$ & 1.0 & 1.0 \\
\hline Resolution $(\AA ̊)^{\mathrm{a}}$ & $34.74-1.72(1.82-1.72)$ & $58.63-1.75(1.85-1.75)$ \\
\hline Unique reflections & 87,266 & 67,271 \\
\hline Multiplicity & $5.2(4.6)$ & $2.8(2.9)$ \\
\hline Completeness (\%) & 99.9 (99.6) & $83.5(79.1)$ \\
\hline$|/ \sigma|$ & $9.2(3.4)$ & $8.8(2.3)$ \\
\hline R merge $(\%)^{b}$ & $13.2(44.0)$ & $8.7(50.4)$ \\
\hline \multicolumn{3}{|l|}{ Refinement } \\
\hline$R_{\text {work }} / R_{\text {free }}(\%)$ & $14.8 / 17.3$ & $15.6 / 19.0$ \\
\hline Protein atoms: no., average B-factor $\left(\AA^{2}\right)$ & $\begin{array}{l}6571 \\
17.9\end{array}$ & $\begin{array}{l}6531 \\
18.1\end{array}$ \\
\hline RMSD Bond angle $\left(^{\circ}\right)$ & 1.052 & 1.353 \\
\hline RMSD Bond length ( $(\AA)$ & 0.0051 & 0.008 \\
\hline
\end{tabular}

a Data within parentheses are for the outermost resolution shell

${ }^{\mathrm{b}} R_{\text {merge }}=\sum_{h} \sum_{\mathrm{i}}\left|I(h)_{i}-\langle I(h)\rangle\right| / \sum_{h} \sum_{i} I(h)_{i}$ where $I(h)_{i}$ is the intensity of reflection $h$ and $\langle I(h)\rangle$ is the average value over multiple measurements

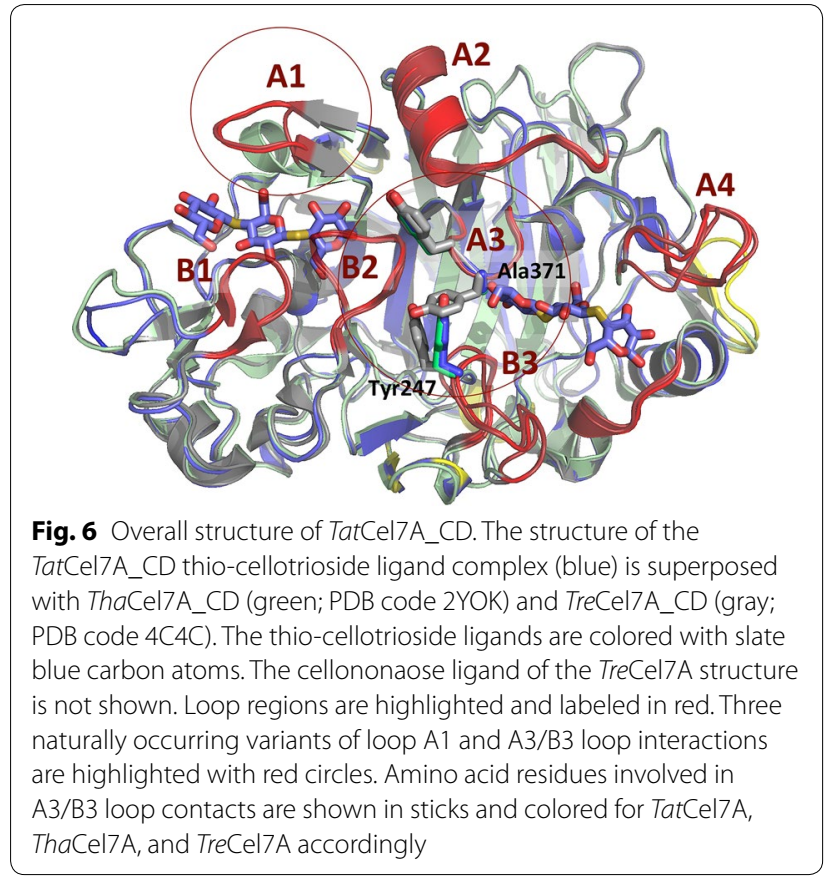

small, but significant, difference in TatCel7A that locally affects protein folding. A one-residue insertion, Gly317, is present in the region 316-319 (section III in the sequence alignment, Figs. 5, 9), where there is a $\beta$-strand-turn in
TreCel7A and ThaCel7A, which supports the A4 loop at the product end of the active site. Also, a glutamine (TreCel7A) or glutamic acid (ThaCel7A) is substituted by Ser316 in TatCel7A, thus introducing a shorter side chain. This substitution, followed by the glycine insertion, disrupts $\beta$-strand interactions, and the 315-317 residues bulge outwards in TatCel7A. Furthermore, Ser316 introduces an N-glycosylation motif (at Asn314) not present in the two other enzymes (Fig. 5). This glycosylation site is close in space to the Asn270 N-glycosylation. Although glycans potentially attached to Asn 314 could not be observed in the TatCel7A structures, a glycan present at this site would be in direct contact with the one at Asn270.

Overall, TatCel7A appears to have fewer secondary structure interactions compared to TreCel7A and ThaCel7A, with shorter $\beta$-strands and $\alpha$-helixes at several locations (see overlay of the structures in Fig. 9). This suggestion is corroborated by a lower number of total native contacts found from the MD simulations (see below).

\section{Molecular dynamics (MD)}

We performed $\mathrm{MD}$ simulations to understand how structural differences in TatCel7A_CD, TreCel7A_CD, and ThaCel7A_CD manifest in protein dynamics. We also examined the effect of bound substrate on protein dynamics for each of the three cellulases, conducting 


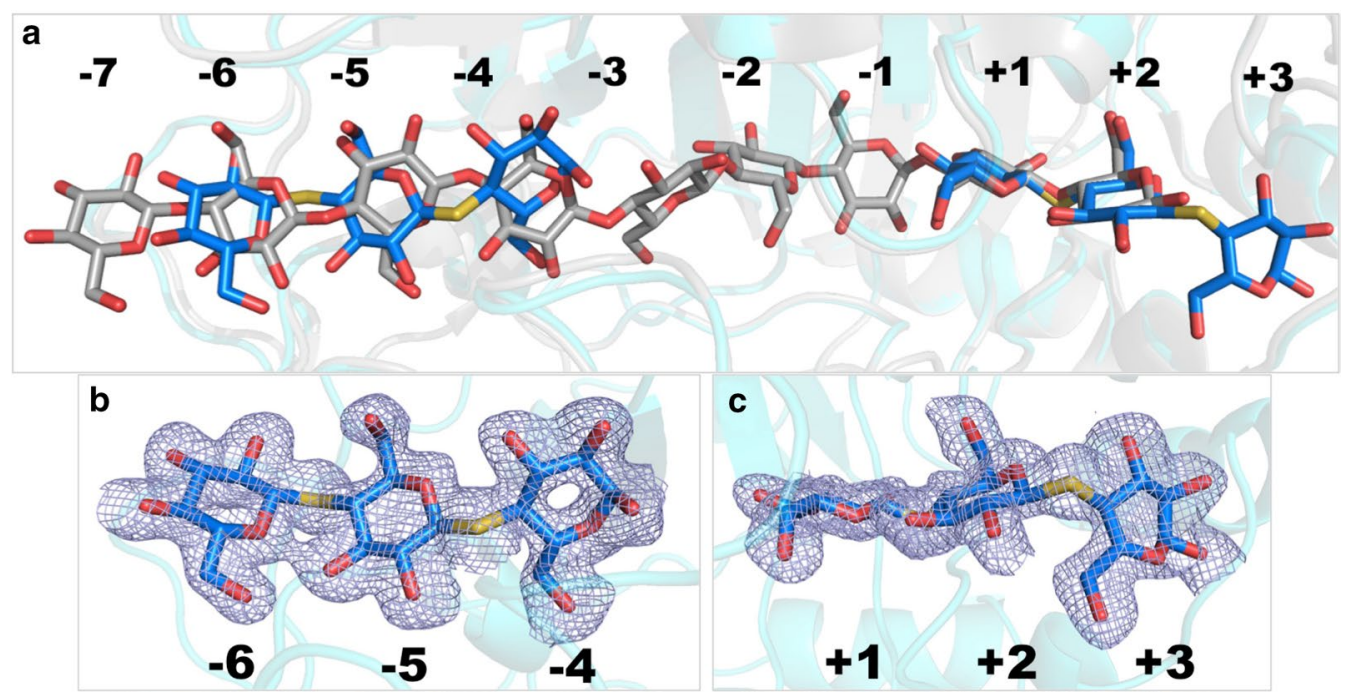

Fig. 7 Glycan binding in the TatCel7A_CD thio-cellotrioside complex structure. a Superposition of ligand binding in the SG3 structure (blue) with cellononaose in the TreCel7A Michaelis complex (4C4C; gray). b Electron density for the ligand at subsites - 6/-5/- 4. c Electron density for the ligand at the $+1 /+2 /+3$ position. The $2 F_{o}-F_{c}$ electron density maps are contoured at $0.26 \mathrm{e} / \mathrm{A}^{3}$

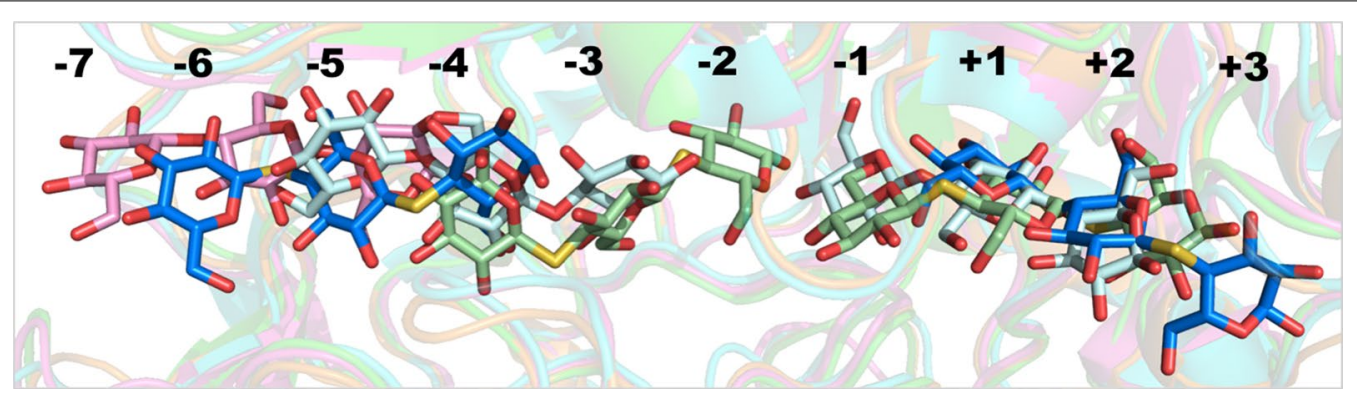

Fig. 8 Superposition of ligands from Cel7/cellotrioside complex structures. The following colors are used: pale cyan, Melanocarpus albomyces Cel7B (2RFZ, chain A); pink, Limnoria quadripunctata Cel7B (4HAQ, chain B); pale green, Cel7A from Scytalidium sp. (ScyCel7A; identical to the enzyme called G. candidum Cel7A in Borisova et al. [3]) (4ZZT); slate blue, TatCel7A. Yellow bonds indicate the 1,4-S-linkage in thio-cellotrioside ligands (from ScyCel7A and TatCel7A)

simulations in the apo state and bound to both cellononaose and crystalline cellulose substrate (Fig. 10).

The root mean square fluctuations (RMSF) of the protein backbone are similar for the three proteins, with elevated RMSF values in the loop regions. The fluctuations are largest around loop A4 (residues 390-410, Figs. 11, 12). TatCel7A is stabilized when complexed with the cellulose microfibril, which is indicated by a decrease in overall fluctuations. The decrease in overall fluctuation is much less pronounced in the other two enzymes (Figs. 11, 12). Inside the binding tunnel, at subsites -5 to -2 , the cellononaose ligand and the chain of the microfibril fluctuate very little in either of the three cellulases; however, towards the ends of the active site, subsites $-7 /-6$ and $+1 /+2$, the ligands naturally fluctuate more, as the ligands are more solvent exposed (Fig. 11d). Higher RMSF in ThaCel7A subsites $-7 /-6$ correlate well with the shorter A1 loop, which makes the entrance to the tunnel wider in this enzyme. Interestingly, this difference is only seen in the simulations with the cellononaose ligand. When complexed with the cellulose microfibril, the ligand fluctuations are nearly the same for the three enzymes along the length of the active site. Throughout all of the MD simulations, either in presence of the crystalline cellulose or while complexed with the cellononaose oligomer in solution, the reducing end of the ligand $(+2$ site) in the active site remained in the $\beta$-anomeric configuration. This configuration arises as a requirement of the implemented carbohydrate force field used for all of our MD simulations, which restricts the 


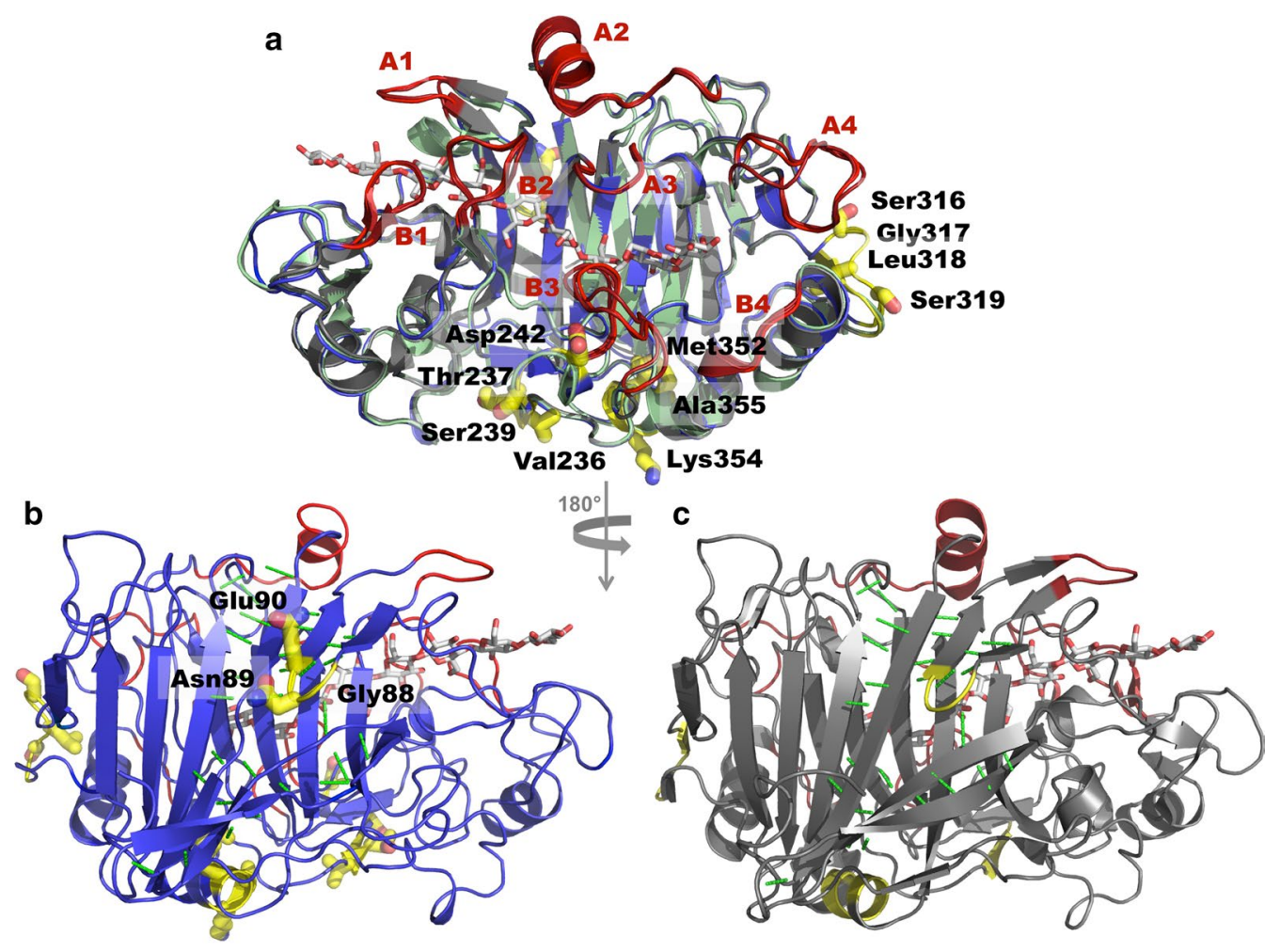

Fig. 9 Comparison of Trichoderma spp. Cel7A structures. a Superposition of TatCel7A_CD APO (blue), ThaCel7A_CD (green; PDB code 2YOK), and TreCel7A_CD (gray; PDB code 4C4C). Loop regions are highlighted in red, and cellononaose from 4C4C is shown with white carbon atoms. Sections I-IV, defined by RCA, are marked in yellow, and amino acid residues with high S-scores in TatCel7A are shown as sticks. b Back side of TatCel7A_CD APO structure. c Back side of TreCel7A_CD. In b, c, polar interactions between $\beta$-strands are shown as green dashed lines

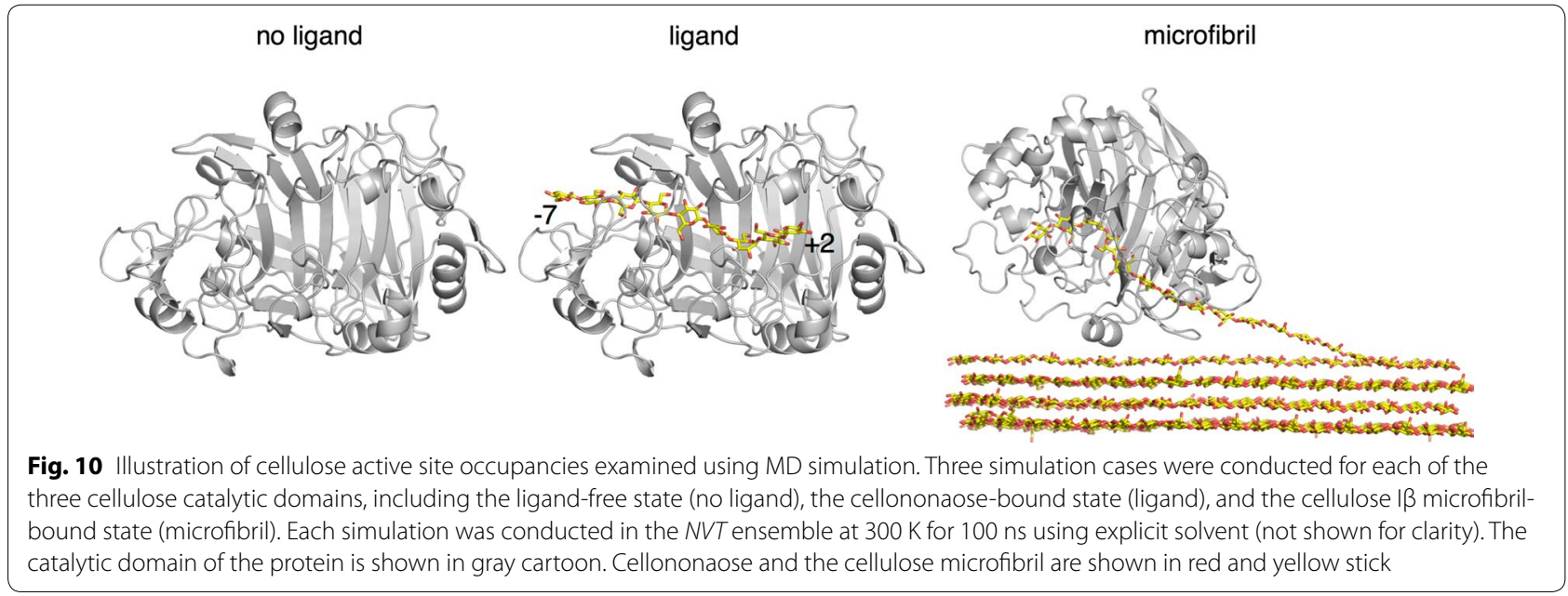

+2 pyranose to the $\beta$-anomeric configuration by virtue of spring constants on the angle and dihedral parameters. While it is feasible that the pyranose rings could temporarily occupy an $\alpha$-anomeric configuration, the energy barrier to do so is quite large.
Despite high sequence and structural similarity, MD simulations reveal distinct differences in terms of loop dynamics between TatCel7A, ThaCel7A, and TreCel7A, illustrated by histograms of distances between tunnelenclosing loops, A3-B2, A3-B3, and B2-B3, respectively, 

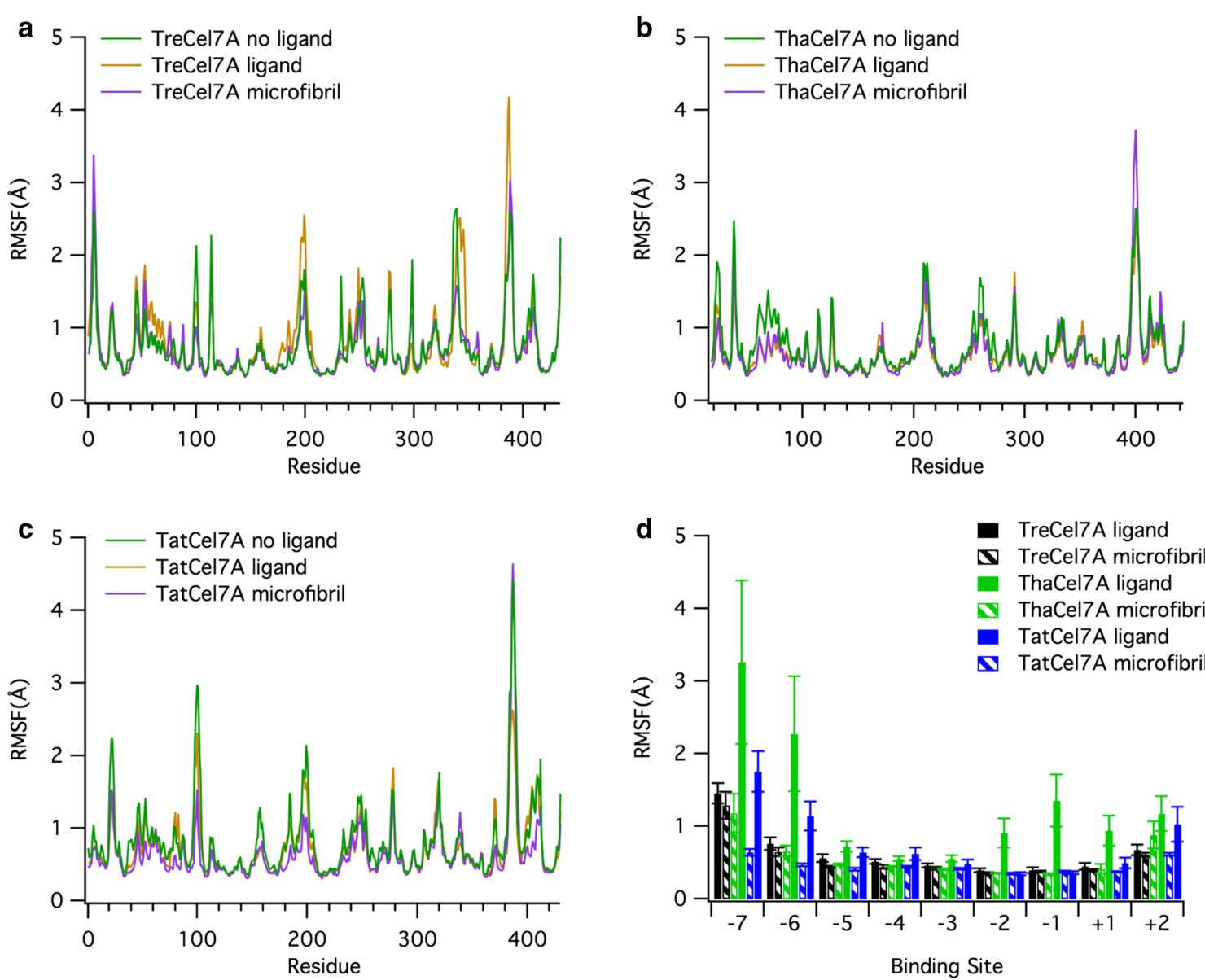

Fig. 11 RMSF from molecular dynamics simulations. The RMSF of the a TreCel7A, b ThaCel7A, and c TatCel7A backbones and $\mathbf{d}$ the ligand and microfibril over 100-ns simulations at $300 \mathrm{~K}$. Error bars shown in $\mathbf{d}$ were obtained through $2.5 \mathrm{~ns}$ block averaging. The molecular simulation data for TreCel7A was reported previously and is shown here for comparison [3]

over the course of simulation (Fig. 13). Most notably, the active site loops of TreCel7A appear to be significantly more stationary than either ThaCel7A or TatCel7A. One conformational state is strongly preferred, as demonstrated by small fluctuations (within $1-2 \AA$ ) of the inter-loop distances around a single peak. Both the A3/ $\mathrm{B} 2$ loops and the A3/B3 loops, 'A' and 'B' designating opposite sides of the active site, remain in direct contact during most of the simulation. In this configuration, the tunnel is physically closed, in the sense that a cellulose chain would only be able to enter or exit through either end of the active site and not "sideways". Occasionally, the loops do separate enough (> $6 \AA$ ) to allow a cellulose chain to pass (Fig. 13a).

The TatCel7A and ThaCel7A enzymes behave similar to TreCel7A with respect to the A3/B2 loop distances, exhibiting small fluctuations around a single peak. However, the $\mathrm{A} 3 / \mathrm{B} 3$ and $\mathrm{B} 2 / \mathrm{B} 3$ loop distances are much more variable than in TreCel7A, likely due to the increased flexibility of loop B3 over B2. In TatCel7A the A3/B3 loop distance was most frequently between 3.5 and 4 $\AA$, though the distance could also hover between 5 and $7 \AA$, indicating that loop B3 moves smoothly between a closed and an open conformation, without any major energy barrier (Fig. 13b). The B3 loop behavior is similar regardless of the presence or absence of ligand/microfibril in the active site, which is a contrast to the B3 loop behavior in TreCel7A where the loop is most often in a closed conformation. Yet another behavior was observed in ThaCel7A, where the B3 loop exhibits a bimodal distribution in the absence of ligand; the B3 loop seemingly flips between two closed conformations. The A3/B3 distance is very short for the primary conformation. With a bound ligand or microfibril, there is no evidence of the short-distance state, and loop B3 appears to fluctuate over a larger range of more open conformations.

To monitor and compare the unfolding process of the Cel7A proteins, MD simulations were also conducted at 


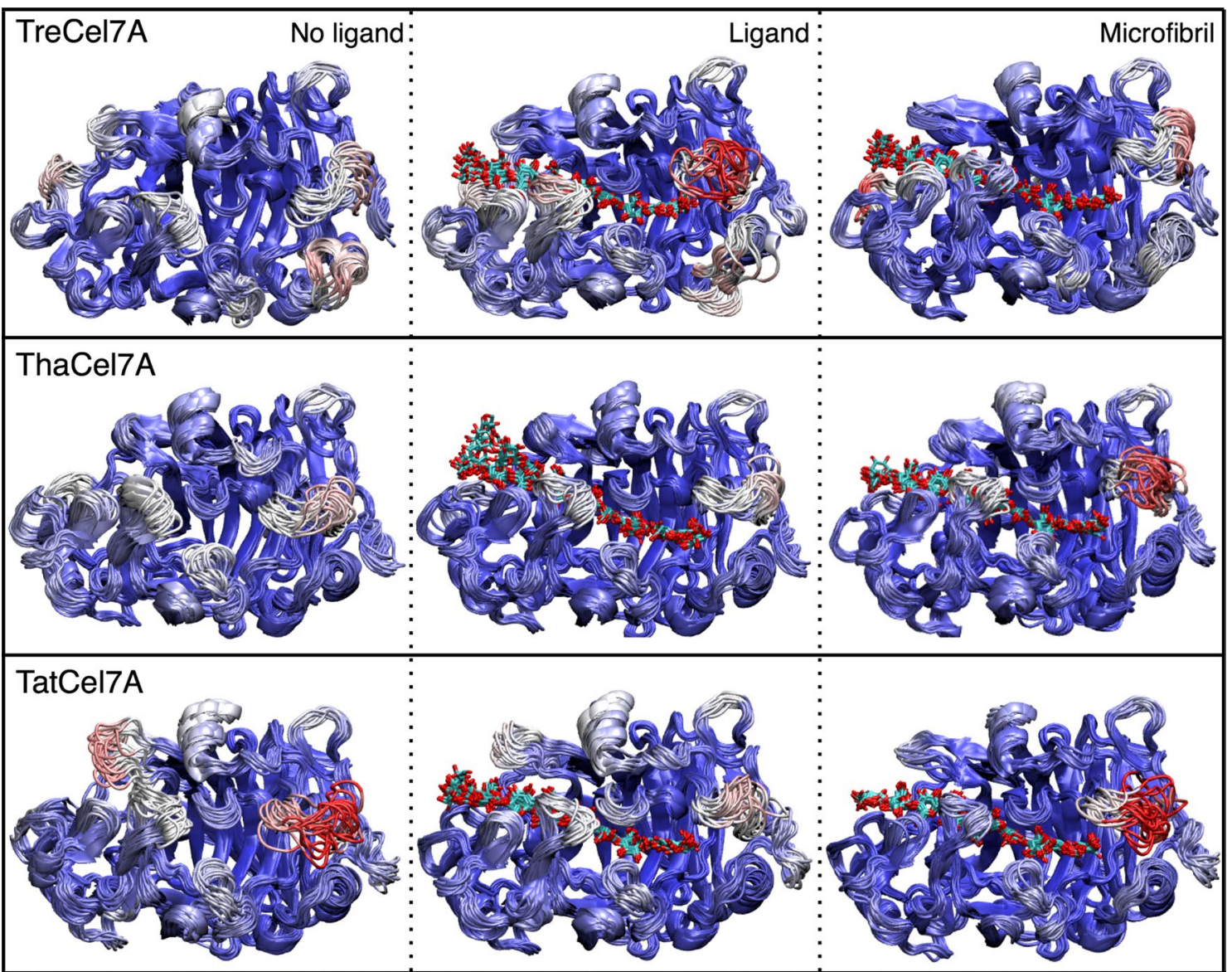

Fig. 12 RMSF comparison of the protein backbone at $300 \mathrm{~K}$. The backbone is colored by a gradient from blue to white to red, representing lower to higher fluctuations. Red regions indicate larger fluctuations (RMSF > $4 \AA$ ). The cellooligosaccharide chain is colored by atom; oxygen is red, and carbon is cyan

elevated temperature ( $475 \mathrm{~K})$ for $15 \mathrm{~ns}$, which was a sufficient length to observe initial unfolding events. From these simulations, we determined the total number of native contacts formed within the protein as a function of time and compared to the number of native contacts formed at $300 \mathrm{~K}$ (Fig. 14). As expected, the total number of native contacts formed in each cellulase was roughly constant at $300 \mathrm{~K}$, i.e., not unfolding. TatCel7A exhibits a lower number of native contacts than either TreCel7A or ThaCel7A (Fig. 14). When the temperature was elevated to $475 \mathrm{~K}$, the number of contacts decreased at about the same rate for all three proteins as they unfolded, suggesting that they are equally sensitive to thermal unfolding.

Additional movie files show the initial unfolding of the protein structure during the $475 \mathrm{~K}$ simulations (see Additional files 2, 3 and, 4 for TatCel7A, TreCel7A, and ThaCel7A, respectively). One region, residues 380-410 containing loops A4 and A2, was among the first parts of the protein to unfold, suggesting that this region may be an important 'hotspot' for initiation of protein unfolding.
In loop A2, there is a short, surface exposed $\alpha$-helix that maintained the helical structure longer in ThaCel7A than in either TreCel7A or TatCel7A, suggesting higher regional thermal stability around loop A2 in ThaCel7A. Another interesting observation is that the B3 loop in TreCel7A and ThaCel7A (not TatCel7A) transiently flipped $\sim 180^{\circ}$ and adopted a conformation where the tip of the loop pointed towards subsite +2 , similar to the conformation observed in the structure of Cel7A from Humicola grisea var. thermoidea (PDB code 4CSI; [5]).

\section{Molecular evolution of Cel7A}

When comparing closely related orthologs, amino acid residues that modulate functional properties of an enzyme are expected to display higher diversity than other positions due to adaptation [35]. Therefore, distribution of amino acid variation was analyzed using RCA [35] of GH7 CBH sequences from two groups of related fungi within the order Hypocreales: Trichoderma spp. (11 sequences) versus Fusarium spp. and Clonostachys rosea 

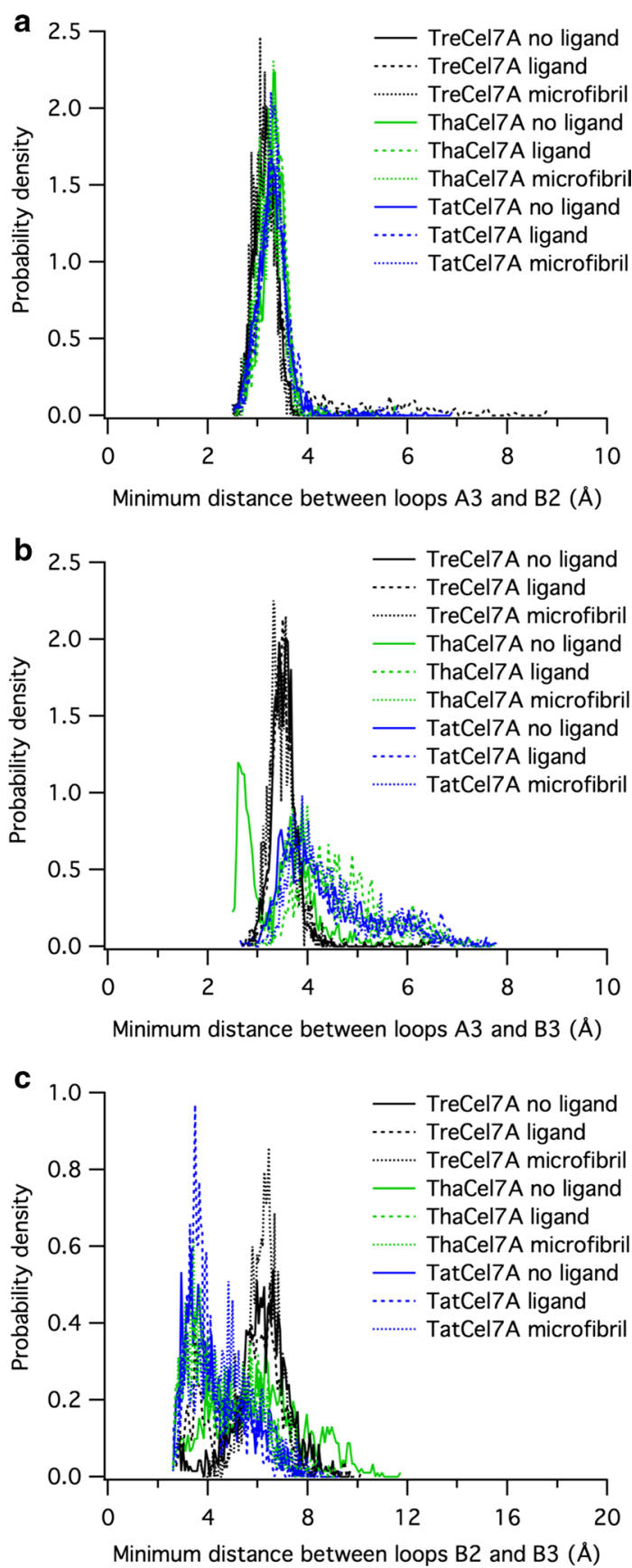

Fig. 13 Active site loop distances from molecular simulation. Histograms of the minimum distances between a loops A3 and B2, b loops A3 and B3, and cloops B2 and B3, evaluated from 100-ns simulation trajectories of TreCel7A, ThaCel7A, and TatCel7A

(6 sequences) (Additional file 1: Figure S8). The orthologous status of the selected sequences was confirmed by a phylogenetic analysis (Additional file 1: Figure S9). We specifically analyzed the alignment for regions displaying signs of type 1 functional divergence (i.e., site conserved in one lineage but variable in the other [36]) in Trichoderma spp. Four sections were identified in the Cel7A alignment-I, II, III and IV (Fig. 12; (Additional file 1: Table S3) - that fulfilled the criteria ( $W$ mean score $\geq 1$ in Trichoderma spp. and $W$ mean score $\leq 1$ in Fusarium spp.). All sites in sections I, II and III are located at the surface of the protein (Fig. 9). Section $I$ is at a $\beta$-turn at one edge of the outer $\beta$-sheet, near the attachment of the linker. Section II comprises a short $\beta$-strand followed by a turn before loop B3 in the sequence and is located at the interface where the B2 and B3 loops are anchored. Section III includes the Gly317 insertion near the product-binding region mentioned above. Section IV includes an amphiphilic $\alpha$-helix, where one side is buried; interestingly, three of the residue positions that display high amino acid diversity $[S$ score $\geq 1$, Met352, Ala355, Leu356 in TatCel7A, (Additional file 1: Table S3)] point into the hydrophobic core, just underneath the $\beta$-strand that carries the catalytic residues. In comparison with the Cel7A alignment of $C$. rosea and five Fusarium species, these sections (I, II, III, and IV) display signs of type 1 functional divergence, with the position conserved in Fusarium spp. but variable in Trichoderma spp. (Fig. 15) [36].

Figure 15 shows the $W$ mean scores from RCA for Trichoderma spp. and Fusarium spp., plotted against residue number (in TatCel7A), compared with temperature factors (B-factors) for mainchain $\mathrm{C} \alpha$ atoms at corresponding positions in the crystal structures of TatCel7A (5O5D), ThaCel7A (2YOK), and TreCel7A (4C4C). $\mathrm{B}$-factors are indicators of protein flexibility and can be directly compared with RMSF from MD simulations. The three enzymes show almost the same pattern, with elevated B-factors in loop regions and the highest values in the A4 loop, all in good agreement with the MD simulation results (Fig. 11). The A4 loop is located at the exit of the tunnel and may affect release of the product, having contacts with section III (Fig. 9). Also noteworthy, loop A4 carries an N-glycosylation site near the product sites that is conserved in all three enzymes. Glycosylation at this site has been observed in structures of TreCel7A (Asn384) and ThaCel7A (Asn380) but was not visible in the TatCel7A structures (Asn384).

\section{Discussion}

Based on observations from initial hydrolysis of BMCC, synergistic conversion of pretreated biomass, and $\mathrm{MD}$ simulation, we suggest that the combination of the A1 and A3 loop motifs is the primary determinant for the observed differences in activity on cellulosic substrates. Initial hydrolysis of BMCC was most rapid with TatCel7A followed by TreCel7A and then ThaCel7A, suggesting that the longer A1 loop, together with the weaker 


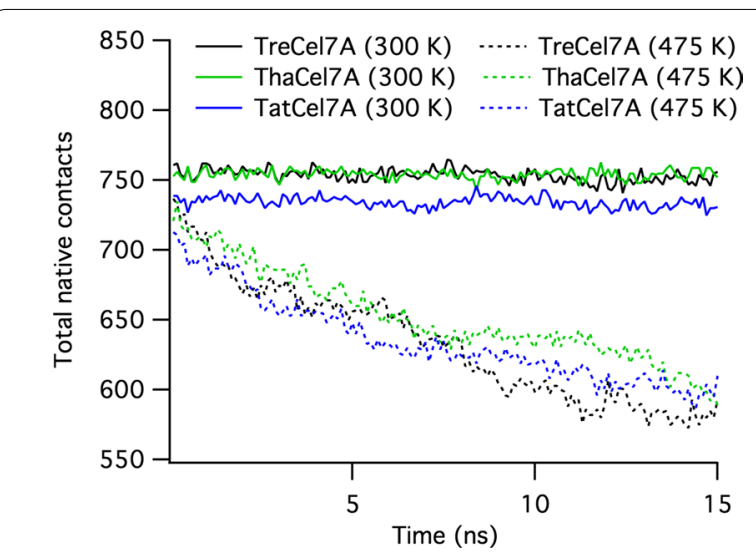

Fig. 14 Total number of native contacts formed by TreCel7A, TatCel7A, and ThaCel7A at 300 and $475 \mathrm{~K}$. The total number of native contacts was determined as an average of three independent MD simulations at two temperatures, $300 \mathrm{~K}$ (solid lines) and $475 \mathrm{~K}$ (dashed lines). The high temperature simulations were performed for $15 \mathrm{~ns}$, whereas the triplicate $300 \mathrm{~K}$ simulations were conducted for $50 \mathrm{~ns}$; only $15 \mathrm{~ns}$ of the $300 \mathrm{~K}$ trajectories are shown here for comparison. In each case, the simulation was conducted without a ligand, in explicit solvent. To determine the total number of native contacts of each trajectory, the number of native contacts formed by each residue was first evaluated. Here, a native contact was defined as any amino acid whose side chain center of geometry was within $6.5 \AA$ of the reference amino residue's $\mathrm{Ca}$. The total number of native contacts is then the sum of the native contacts formed by all residues in the protein
A3-B3 loop interaction (Tyr-Ala rather than Tyr-Tyr at the tip of loop A3), may be superior under these experimental conditions. Polikarpov et al. showed that deletion of three residues at the tip of the A1 loop in ThaCel7A makes the entrance to the tunnel more open, and the replacement of one Tyr with Ala at the tip of loop A3 (relative to TreCel7A) increases the flexibility of the opposing B3 loop [21]. Our MD simulations of TreCel7A and ThaCel7A, conducted here for comparison to TatCel7A, are in good agreement with those results. As with ThaCel7A, the B3 loop of TatCel7A is more flexible and opens more frequently than in TreCel7A (Fig. 13). ThaCel7A and TatCel7A share A3 loop features, whereas the A1 loop is similar in TatCel7A and TreCel7A. Thus, the most likely major determinant of the observed functional differences in initial crystalline cellulose hydrolysis is the longer A1 loop present in TatCel7A and TreCel7A.

Although TatCel7A showed higher $k_{\text {cat }}$ in initial hydrolysis of BMCC, the processive model kinetic parameter fit to the progress curves did not reveal clear differences that could be readily correlated with protein structure and dynamics. The apparent processivity values (74-97) are in the same range, but somewhat higher than found by alternative methods $(66-70)$ [17, 37, 38]. Also, both $k_{\text {on }}$ and $k_{\text {off }}$ values are higher in our case. However, the

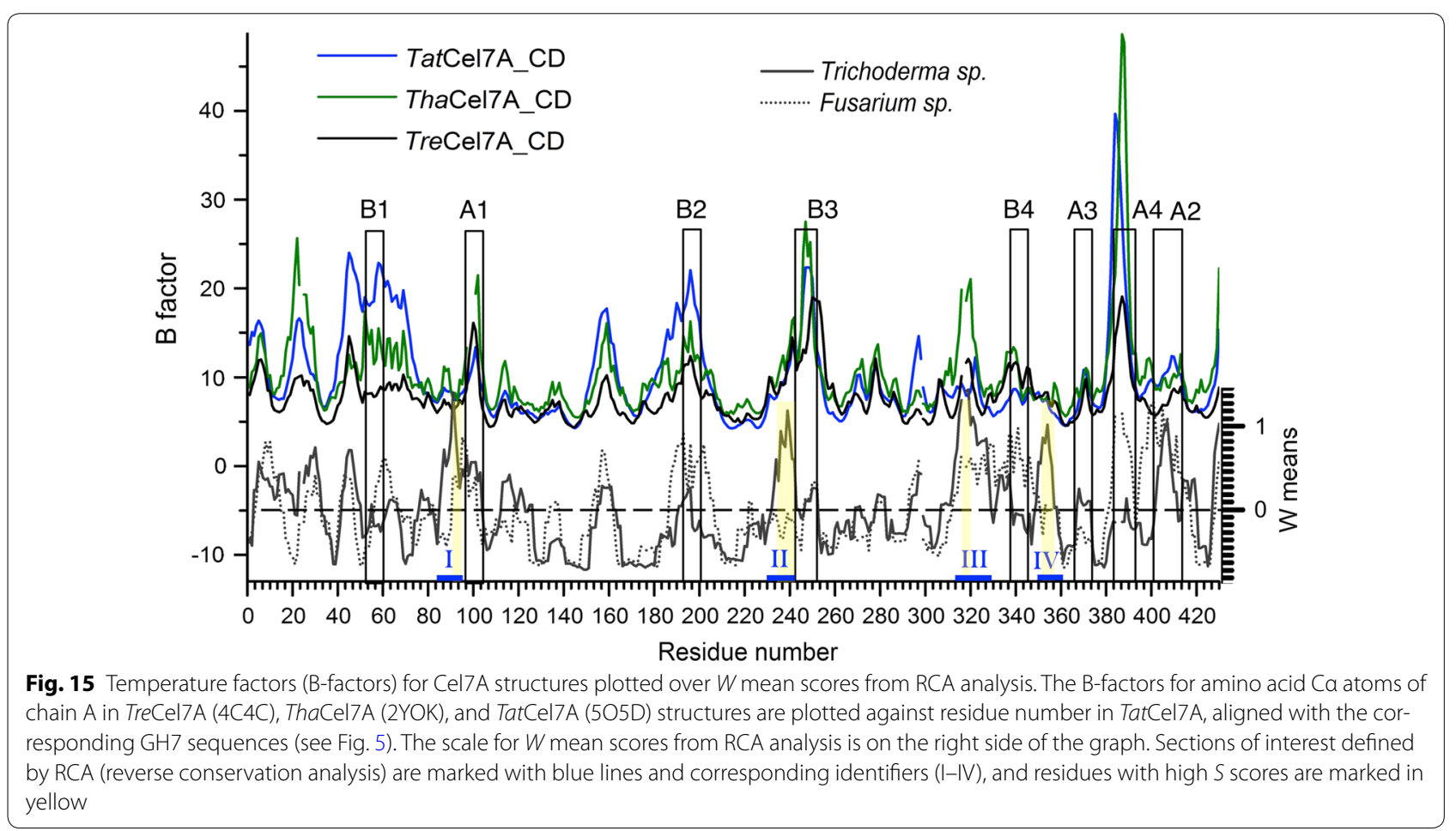


studies cited above employed other cellulose substrate preparations (e.g., reduced bacterial cellulose and Avicel) and may not be directly comparable. In our case, the $k_{\text {off }}$ value is comparable or lower for TreCel7A_CD compared to the full-length enzyme. This is in contrast to Kont et al. who reported the opposite [38]. However, in a study by Cruys-Bagger et al. [32, 33], similar $k_{\text {off }}$ values were found for TreCel7A and TreCel7A_CD. In that study, the authors suggested that the main energy barrier for dissociation is the release of the cellulose strand from the catalytic domain. In our current study, we find a slightly lower $k_{\text {off }}$ value for the examined enzymes without a linker and CBM. We cannot explain this observation, but suspect that it may be related to the low DP of the substrate. With an estimated DP of around 120 glucose units and an apparent processivity of 70-90, the enzyme would, in most cases, 'fall off' when the entire cellulose chain has been hydrolyzed, rather than dissociating from the chain along the process.

When comparing the performance of the Cel7s in synergistic conversion of pretreated biomass to soluble sugar, both TatCel7A and ThaCel7A gave higher yields of soluble sugar than TreCel7A, indicating that weaker A3-B3 interaction and, hence, higher B3 loop flexibility is beneficial to conversion. The length of the A1 loop may be of less importance, although TatCel7A, with the longer A1 loop, appears to be slightly more efficient than ThaCel7A. Though our data implicates loops A1 and A3 in variable efficiency, we cannot rule out that other differences between the three enzymes may also influence their performance, such as linker length, glycosylation, or other residue substitutions that may affect the protein dynamics.

The B3 loop is anchored by disulfide bridges at both ends (Cys243 and Cys256 in TatCel7A) and is almost identical in sequence in the three enzymes, except for Asp-Asn conservative replacements at positions 249 and 250. In TatCel7A (and similarly in ThaCel7A), Asn249 hydrogen bonds to the nearby Asp241, which would stabilize the loop and reduce fluctuations. Asn249 is replaced by Asp249 in TreCel7A, which, in some structures, forms a short distance, low-barrier hydrogen bond with Asp241 called an acid pair [39]. Such acid pair interactions are $\mathrm{pH}$ dependent and more distance restrained [40], which may contribute further to the restriction of B3 loop mobility in TreCel7A. Interestingly, the variable RCA defined section II before loop B3 includes the hydrogen-bonding partner, Asp241, and the nearby Ser239. The latter is replaced by Glu239 in TreCel7A, which is stabilized in turn by metal ion coordination together with His206. This may indicate that fine-tuning of B3 loop flexibility represents an important evolutionary target in Trichoderma spp. Cel7 proteins.
We were surprised to find that TatCel7A exhibits significantly lower activity against $p$ NP-Lac, while it was about the same for TreCel7A and ThaCel7A. The enzyme kinetics results show that this is mainly due to a significantly lower $k_{\text {cat }}$ (Table 1 ). Also, the $K_{\mathrm{M}}$ value is slightly higher, giving a catalytic efficiency $\left(k_{\text {cat }} / K_{\mathrm{M}}\right)$ for TatCel7A of only about $25 \%$ compared to TreCel7A and ThaCel7A. No obvious clues are evident from structural comparison, though, as to why that is the case. The three structures are practically identical at the subsites $(-2 /-1 /+1)$ where $p$ NP-Lac should bind for hydrolysis. However, $p$ NP-Lac is an artificial chromogenic model substrate and may be a poor representative of function in Nature. Interestingly, a similar discrepancy in $p$ NP-Lac activity has been reported previously for two close GH7 CBH orthologs from Amoebozoa [18]. Cel7A from Dictyostelium discoideum exhibited lower thermal stability and about half of the specific activity against $p$ NP-Lac compared to $D$. purpureum Cel7A, despite $80 \%$ sequence identity.

The three enzymes showed similar $\mathrm{pH}$ dependence, with activity optimum around $\mathrm{pH} 4.5$ and sensitivity to inactivation above neutral $\mathrm{pH}$. This indicates that all the three species, T. atroviride, T. reesei, and T. harzianum, are adapted to biomass degradation at rather acidic conditions, without strong evolutionary pressure on their Cel7A enzymes towards action at higher pHs.

TatCel7A appears to be more temperature sensitive than either TreCel7A or ThaCel7A, with a slightly lower temperature optimum and more rapid irreversible inactivation at elevated temperature. This is likely a function of fewer secondary structure interactions in TatCel7A relative to TreCel7A and ThaCel7A, as observed by structural comparison and a lower number of native contacts found in the MD simulations. In particular, the A2-A4 region that appears to be a hotspot for initiation of unfolding seems to unfold faster in TatCel7A in the high-temperature MD simulations (see Additional file 2: Movie S1). Notably, though, the two regions on the backside of the protein where TatCel7A deviates structurally, i.e., near the linker attachment $(13-17,28-30)$ and around the Gly317 insertion (420-422), did not show any clear signs of unfolding more readily. Overall, the backside of the proteins remained remarkably stable throughout the high-temperature simulations, in contrast to large mobility of the extended loops along the active site.

The higher yield of soluble sugar obtained for TatCel7A vs. TreCel7A in the experiments on pretreated biomass suggests that this enzyme may be useful for industrial conversion of biomass. The lower temperature stability could be addressed by engineering a more stable variant inspired by TreCel7A or any other more thermostable GH7 CBH $[5,9]$. The improvement of thermal stability of TreCel7A by directed evolution has recently 
been reported, where the most stable variant contains 18 mutations and exhibited a $10.4{ }^{\circ} \mathrm{C}$ increase in protein melting temperature [41]. Based on that study and the results herein, we propose that the primary region to target would be the $\mathrm{A} 2-\mathrm{A} 4$ region in order to stabilize the $\alpha$-helix of the A2 loop while taking into account product - enzyme interactions at the exit of the tunnel. It should be noted, though, that irreversible inactivation depends not only on protein unfolding, but also on the exposure and aggregation of hydrophobic regions of the protein, which is difficult to predict.

\section{Conclusions}

We have determined the three-dimensional structure and analyzed the properties of TatCel7A, the major secreted protein from T. atroviride, and compared these results to the close orthologs: ThaCel7A and TreCel7A. All three proteins are very similar in sequence, structure, and several other aspects, yet, subtle differences are manifested in terms of stability, activity, and protein dynamics. Such differences, for example, in initial hydrolysis rates of $\mathrm{BMCC}$ and synergistic conversion of pretreated biomass, may lead to significant effects in the large-scale process applied for biomass conversion.

\section{Methods}

\section{Preparation of Trichoderma Cel7 enzymes}

The fungal strains T. atroviride IOC 4503 and T. harzianum IOC 3844 were obtained from the Culture Collection of Filamentous Fungi at the Oswaldo Cruz Institute (CCFF/IOC) in Brazil. They were grown on potato dextrose agar plates at $25{ }^{\circ} \mathrm{C}$ until dense sporulation developed (about 1 week) to produce fresh spores for culture inoculation. Submerged cultivation in distiller's spent grain medium [42] with $1 \% \mathrm{w} / \mathrm{v}$ Avicel cellulose as a carbon source was undertaken for 6 days at $30{ }^{\circ} \mathrm{C}$ in a rotary incubator at $80 \mathrm{rpm}$; the cultivation took place in $2.8 \mathrm{~L}$ side-baffled Fernbach flasks (Bellco Glass Inc., Vineland, NJ, USA), each with $0.6 \mathrm{~L}$ medium containing: 6 g dry distillers spent grain, $9 \mathrm{~g} \mathrm{KH}_{2} \mathrm{PO}_{4}, 3 \mathrm{~g}\left(\mathrm{NH}_{4}\right)_{2} \mathrm{PO}_{4}, 0.36 \mathrm{~g}$ $\mathrm{MgSO}_{4}$, and $0.36 \mathrm{~g} \mathrm{CaSO}_{4}$. The $\mathrm{pH}$ was measured daily. On day 2, the $\mathrm{pH}$ dropped to around $\mathrm{pH} 3.5-3.8$ for both fungi and was adjusted to $\mathrm{pH} 5$ by addition of $2 \mathrm{~g} \mathrm{~K}_{2} \mathrm{HPO}_{4}$ to each flask. Upon harvest, the cultures were filtrated on Whatman GF/B glass fiber filters $(\sim 1 \mu \mathrm{m}$ pore size $)$ followed by 0.45 and $0.2 \mu \mathrm{m}$ sterile filtration.

The culture filtrate was desalted on Bio-Gel P-6DG (BioRad; $500 \mathrm{~mL}$ column) to $10 \mathrm{mM}$ potassium phosphate buffer, $\mathrm{pH}$ 6.0, then applied to a DEAE Sepharose Fast Flow column (GE Healthcare; $\mathrm{CV}=200 \mathrm{~mL}$ ) and eluted with a gradient up to $0.5 \mathrm{M} \mathrm{NaCl}$ in the same buffer. Fractions containing $p$ NP-Lac activity were pooled, desalted, and applied to a SOURCE 30Q column
(GE Healthcare; $\mathrm{CV}=25 \mathrm{~mL}$ ) eluted with a $10-500 \mathrm{mM}$ potassium phosphate, $\mathrm{pH}$ 6.0, gradient. Fractions with activity against $p$ NP-Lac were collected and subjected to SDS-PAGE analysis to estimate the purity of the Cel7 protein. The yield of purified enzyme per liter of culture was $70 \mathrm{mg}$ for TatCel7A and $85 \mathrm{mg}$ for ThaCel7A.

TatCel7A_CD used for crystallization was prepared from the T. atroviride strain IMI 206040, kindly donated by Dr. Alexander Golubev (Petersburg Nuclear Physics Institute, Gatchina, Russia). Cultivation, protein purification, domain cleavage with papain and enzymatic N-deglycosylation were performed as previously described [3]. The solved crystal structure confirms that the protein sequence is identical to that of TatCel7A from T. atroviride strain IOC 4503, at least in the catalytic domain.

For all TreCel7A experiments except the PCS hydrolysis experiments, TreCel7A was obtained from T. reesei strain QM9414 as described [31, 43]. For the PCS hydrolysis experiments, TreCel7A was recombinantly produced in the T. reesei AST1116 constitutive expression system and purified to homogeneity as detailed in [44].

For preparation of the Cel7 catalytic domains, the CBM-linker portion of the full-length enzymes were removed by partial proteolysis using papain as previously described [3], followed by size-exclusion chromatography on a HiLoad Superdex 75 16/60 column (GE Healthcare) with $10 \mathrm{mM}$ sodium acetate, $\mathrm{pH} 5.0,0.15 \mathrm{M} \mathrm{NaCl}$ as eluent. Purified proteins were concentrated and stored in $10 \mathrm{mM}$ sodium acetate, $\mathrm{pH} 5.0$, at $-20{ }^{\circ} \mathrm{C}$. Protein concentrations were determined spectrophotometrically at $280 \mathrm{~nm}$ using theoretical extinction coefficients calculated from amino acid sequences using the ProtParam web service (ExPASy ProtParam http://web.expasy.org/ protparam/): TreCel7A, $86760 \mathrm{M}^{-1} \mathrm{~cm}^{-1}$; TreCel7A_CD, $80550 \mathrm{M}^{-1} \mathrm{~cm}^{-1}$; TatCel7A, $86760 \mathrm{M}^{-1} \mathrm{~cm}^{-1}$; TatCel7A $\mathrm{CD}, 80550 \mathrm{M}^{-1} \mathrm{~cm}^{-1}$; ThaCel7A, $90770 \mathrm{M}^{-1} \mathrm{~cm}^{-1}$; ThaCel7A_CD, $80550 \mathrm{M}^{-1} \mathrm{~cm}^{-1}$.

\section{Temperature and $\mathrm{pH}$ dependence, enzyme kinetics and cellobiose inhibition}

Hydrolytic activity measurements were carried out in triplicate in 96-well microtiter plates using $p$ NP-Lac as substrate. Reaction mixtures of $150 \mu \mathrm{L}$ contained $50 \mathrm{mM}$ buffer ( $\mathrm{pH} 3-7$, phosphate-citrate; $\mathrm{pH} 7-8$, potassium phosphate; $\mathrm{pH} 8-9$, sodium borate), $2 \mathrm{mM}$ of $p$ NP-Lac and $0.15 \mu \mathrm{M}$ of the enzyme (TreCel7A_CD, ThaCel7A CD, or TatCel7A_CD). The reaction was quenched by adding $150 \mu \mathrm{L}$ of $0.5 \mathrm{M}$ sodium carbonate, followed by measurement of absorbance at $405 \mathrm{~nm}$ using an Eon Multiplate Reader. The rate of $p$ NP release was calculated using an extinction coefficient of $18.3 \mathrm{mM}^{-1} \mathrm{~cm}^{-1}$.

The $\mathrm{pH}$ dependence of hydrolytic activity was determined in the range of $\mathrm{pH} 3.0-8.0$. The reactions were 
incubated at $30{ }^{\circ} \mathrm{C}$ for $30 \mathrm{~min}$. In $\mathrm{pH}$ stability experiments, the enzymes were pre-incubated at $40{ }^{\circ} \mathrm{C}$ at pHs from $\mathrm{pH} 3.0-9.5$ for $20 \mathrm{~h}$, followed by $p$ NP-Lac activity measurement at $30{ }^{\circ} \mathrm{C}$ and $\mathrm{pH} 4.5$ using a 30 -min incubation.

For temperature dependence of activity, the reactions were incubated in the temperature range of $20-75{ }^{\circ} \mathrm{C}$ for $1 \mathrm{~h}$ at $\mathrm{pH} 4.5$. The reaction components were pre-cooled and mixed on ice, then transferred into the thermostat equilibrated at the desired temperature. For assessment of thermal inactivation, the enzymes were pre-incubated at 60,65 , and $70{ }^{\circ} \mathrm{C}$ at $\mathrm{pH} 4.5$. Aliquots were taken at indicated time points up to 90 min and cooled on ice, followed by determination of residual hydrolytic activity against $p$ NP-Lac at $30^{\circ} \mathrm{C}, \mathrm{pH} 4.5$, and $1 \mathrm{~h}$ incubation time.

Experiments for determination of enzyme kinetics parameters $V_{\max }$ and $K_{\mathrm{M}}$ for $p$ NP-Lac as substrate and inhibition constants $K_{\mathrm{i}}$ for cellobiose were done in 96-well microtiter plates as described above. Reaction mixtures containing TreCel7A_CD, ThaCel7A_CD, or TatCel7A_CD $(0.12,0.22,0.12 \mu \mathrm{M}$, respectively), $50 \mathrm{mM}$ sodium phosphate citrate buffer, $\mathrm{pH} 4.5$, and $p$ NP-Lac at $0.1,0.2,0.4,0.67,1.2,2,3,4,5$, and $6.7 \mathrm{mM}$ concentration, without and with $100 \mu \mathrm{M}$ cellobiose, were incubated for $1 \mathrm{~h}$ at $30{ }^{\circ} \mathrm{C}$. Nonlinear regression fitting was accomplished using the Excel Solver add-in (Microsoft, Richmond, WA, USA). Weighted squared residuals were calculated for each data point using a statistical weighting scheme, $\left[\left(v_{\text {obs }}-v_{\text {calc }}\right)^{2} / v_{\text {calc }}\right]$, where $v_{\text {obs }}$ is the observed reaction rate, and $v_{\text {calc }}$ is the rate calculated from kinetic parameters $\left(V_{\max }, K_{\mathrm{M}}, K_{\mathrm{i}}\right)$. The kinetic parameters were fit towards the minimized sum of residuals using the GRG nonlinear solving method within Solver. Mixed inhibition was first evaluated. In all cases, the uncompetitive $K_{\mathrm{i}}$ was more than an order of magnitude higher than the competitive $K_{\mathrm{i}}$, indicating that cellobiose acted as a competitive inhibitor. Therefore, the final values shown in Table 1 were derived by fitting the data to the Michaelis-Menten expression for competitive inhibition (see Additional file 1: Figure S2). The RMSD between $v_{\text {calc }}$ and $v_{\text {obs }}$ was used as indicator of experimental error (3.4, 4.0 and 2.4\% for TreCel7A_CD, TatCel7A_CD, and ThaCel7A_CD, respectively).

\section{Initial hydrolysis of cellulose}

The initial hydrolysis of cellulose was measured using Biosensor equipment at Roskilde University, Denmark. Bacterial microcrystalline cellulose (BMCC) from Acetobacter xylinum was prepared from bacterial cellulose (BC) extracted from commercially available Nata de Coco as described [45]. The degree of polymerization of such BMCC has been determined at 114 glucose units [45]. Hydrolysis of BMCC was monitored by cellobiose product formation. The concentration of cellobiose was measured in real time with cellobiose dehydrogenasemodified carbon paste electrodes as described in detail by Cruys-Bagger et al. [32, 46]. The sensor had a response time and lower detection limit of $4 \mathrm{~s}$ and $60 \mathrm{nM}$, respectively. All reactions were carried out in $50 \mathrm{mM}$ sodium acetate $\mathrm{pH} 5.0$ at $25{ }^{\circ} \mathrm{C}$ with stirring. The reaction mixture contained $3.3 \mathrm{~g} / \mathrm{L}$ of $\mathrm{BMCC}$ and $50 \mathrm{nM}$ enzyme (TreCel7A, TreCel7A_CD, ThaCel7A, TatCel7A, and TatCel7A_CD). The experimental data (time interval 0-200 s) was fit to the processive model shown in Additional file 1: Figure S4A. The model consists of three rateconstants, $k_{\text {on }}, k_{\text {cat }}$, and $k_{\text {off }}$, and an apparent processivity parameter, $n$. For further detail, see Additional file 1.

\section{Pretreated corn stover (PCS) hydrolysis}

Corn stover was harvested in 2009 in Hurley County, $\mathrm{SD}$, USA, and was knife milled to pass a $19 \mathrm{~mm}$ (0.75 in) round screen and stored indoors in $200 \mathrm{~kg}$ lots at NREL (National Renewable Energy Laboratory, Golden, CO, USA). The compositional analysis of the native corn stover is given by Chen et al. [47]. Dilute acid pretreated corn stover (PCS) was prepared and analyzed by NREL standard laboratory analytical procedures [48], with PCS composed of $64.2 \%$ dry weight glucan. The PCS substrate was suspended in $20 \mathrm{mM}$ sodium acetate buffer at $\mathrm{pH}$ 5.0. Digestions were conducted at $40{ }^{\circ} \mathrm{C}$ in high-performance liquid chromatography (HPLC) vials placed in a rotator at $10 \mathrm{rpm}$ up to $96 \mathrm{~h}$. An amount of PCS substrate equivalent to $8.5 \mathrm{mg}$ of glucan was added to the enzymatic cocktail consisting of each of the GH7 CBHs, endoglucanase I from $T$. longibrachiatum (Megazyme Co., Bray, Ireland), and $\beta$-glucosidase from Aspergillus niger (Megazyme Co., Bray, Ireland) at a concentration of $28,1.9$, and $0.5 \mathrm{mg}$ protein/g of glucan, respectively. The ratio and dosage of enzymes used here represent one of the standard conditions developed and used at NREL to assay the performance of Cel7 enzymes in NREL PCS conversion $[49,50]$. Adjustment of the biomass assay aliquots to $1.7 \mathrm{~mL}$ final volume resulted in a cellulose concentration of $5.0 \mathrm{mg} / \mathrm{mL}$ and a $\mathrm{GH} 7 \mathrm{CBH}$ concentration of $0.14 \mathrm{mg} / \mathrm{mL}$, corresponding to $2.5 \mu \mathrm{M}$ for TreCel7A. Sugar analyses were performed by HPLC as reported in [44]. Experiments were performed in duplicate.

\section{X-ray crystallography}

Crystallization experiments were carried out with the deglycosylated catalytic domain TatCel7A_CD. Screening for crystallization conditions was performed in 96-well sitting drop trays using a Mosquito crystallization robot (TTP Labtech, UK). The most promising crystallization hits were obtained at room temperature with Hampton polyethylene glycol (PEG)/Ion screen. The 
final optimized conditions contained $5 \mathrm{mM} \mathrm{NiCl}_{2}, 0.1 \mathrm{M}$ HEPES pH 7.0, and 20\% w/v PEG 3350 as a precipitant. Crystals used for data collection were grown by sitting drop vapor diffusion under the same conditions after 1:1 mixing of precipitant with $4.8 \mathrm{mg} / \mathrm{mL}$ TatCel7A_CD in $20 \mathrm{mM}$ Bis-Tris buffer, $\mathrm{pH}$ 7.0. Cellobiose was added to the crystallization drops for the APO structure but is not seen in the structure. The SG3 structure complex was obtained from co-crystallization drops with $5 \mathrm{mM}$ 4,4'-dithio-cellotriose.

$\mathrm{X}$-ray diffraction data were collected at $100 \mathrm{~K}$ at the synchrotron beamline ID23-1, ESRF, Grenoble, France, as indicated in Table 3. The data were integrated with XDS [51] and scaled using the programs Scala and Aimless in the CCP4 suite [52]. The initial TatCel7A_CD structure model was solved by molecular replacement using PHASER [53] and a structure of TreCel7A_CD as the search model (PDB code 1CEL).

REFMAC5 [54] was used for structure model refinements, and manual model rebuilding was performed with Coot $[55,56]$ using maximum likelihood sigma-averageweighted $2 F_{\mathrm{o}}-F_{\mathrm{c}}$ electron density maps [56]. For crossvalidation by $R$ and $R_{\text {free }}$ calculations, $5 \%$ of the data were excluded from the structure refinement [57]. Solvent molecules were automatically added using the automatic water picking function in the ARP/wARP package [58]. Picked water molecules were selected or discarded manually by visual inspection of $2 F_{\mathrm{o}}-F_{\mathrm{c}}$ and $F_{\mathrm{o}}-F_{\mathrm{c}}$ electron density maps. The coordinates for the two final TatCel7A_CD structure models and the structure factors have been deposited in the Protein Data Bank (http:// wwpdb.org/) with accession codes 5O5D and 5O59.

\section{Molecular dynamics simulations}

For the catalytic domain of each enzyme (TatCel7A, TreCel7A, and ThaCel7A), three ligand-bound states were modeled: without a ligand (no ligand), bound to cellononaose (ligand), and bound to a cellulose I $\beta$ microfibril (microfibril) (Fig. 10). The cellulase structures used for MD simulations were obtained from crystal structures deposited in the Protein Data Bank: PDB ID 4C4C for TreCel7A [59], 2YOK for ThaCel7A [21], and 5O5D for TatCel7A. The three simulations of TreCel7A at $300 \mathrm{~K}$ have been previously reported [3] and are presented here again for direct comparison to ThaCel7A and TatCel7A dynamics. Additionally, we carried out a set of MD simulations at an elevated temperature, $475 \mathrm{~K}$, considering each cellulase in the ligand-free "Apo" state in solution, to examine the unfolding process of the enzymes and to locate regions vulnerable to increased temperature (hotspots).

To build the TreCel7A apo simulation, the cellononaose ligand was removed from the active site of the catalytic domain. For the cellononaose-bound state, the cellononaose ligand from $4 \mathrm{C} 4 \mathrm{C}$ was retained from the crystal structure $(4 \mathrm{C} 4 \mathrm{C})$, occupying the active site from -7 to +2 sites (Fig. 10). The TreCel7A microfibril complex was constructed by docking the cellononaose-bound catalytic domain on the hydrophobic face of the cellulose $1 \beta$ crystal matrix, where a single chain had been decrystallized as previously described [3]. In each TreCel7A case, the mutated Gln217 was reverted to the wild-type glutamic acid. Additional details of the modeling procedure for the TreCel7A simulations can be found in our previous work [3]. The ThaCel7A and TatCel7A ligand-free simulation sets were constructed from the apo crystal structures. The cellononaose-bound ThaCel7A and TatCel7A models were constructed by aligning the protein backbone with TreCel7A (4C4C) and adopting the coordinates of the $4 \mathrm{C} 4 \mathrm{C}$ cellononaose; structural alignment was performed using PyMOL [60]. The ThaCel7A and TatCel7A microfibril complexes were constructed as described for TreCel7A above and previously [3].

In each model, only the catalytic domains of cellulases were simulated, excluding the glycosylated linker and the carbohydrate-binding module. Additionally, the glycans attached to the catalytic domains were omitted from the models, as they have relatively limited effects on the protein dynamics over MD-simulation time scales [61]. pKa calculations, using the $\mathrm{H}++$ webserver, and visual inspection were used to determine the protonation states of the titratable residues at $\mathrm{pH} 5.0$ with internal and external dielectrics of 10 and 80, respectively [62-64]. Disulfide bonds were defined according the PDB structures. CHARMM was used to construct and explicitly solvate the systems with the water molecules $(80 \AA \times 80$ $\AA \times 80 \AA$ for no ligand and ligand systems; $135 \AA \times 100$ $\AA \times 90 \AA$ for the microfibril complexes) [65]. $\mathrm{Na}^{+}$ions were added to ensure the charge neutrality of the system, avoiding the self-energy artifact $[66,67]$.

Minimization and equilibration simulations were conducted in CHARMM using the CHARMM36 force field to define the protein and carbohydrate behavior and the modified TIP3P force field for water [68-73]. Minimization of each system was conducted in three steps: (1) keeping the protein, the ligand (if present), and the microfibril (if present) fixed and allowing the water molecules to move freely, then (2) keeping only the protein fixed, allowing the remainder of the system to move freely, and (3) allowing every atom in the system to move freely without any restraint. Each of the three minimization steps used 1000 steps of steepest decent (SD) minimization. Following minimization, the systems were heated from 100 to $300 \mathrm{~K}$ in the NVE ensemble for 20 ps using $50 \mathrm{~K}$ temperature increments every $4 \mathrm{ps}$. The systems were then density equilibrated in the NPT ensemble 
at $300 \mathrm{~K}$ for $100 \mathrm{ps}$. Data collection simulations of $100 \mathrm{~ns}$ were conducted using NAMD in the NVT ensemble at $300 \mathrm{~K}$ with a time step of $2 \mathrm{fs}[65,74]$. Evaluation of the RMSD of the protein backbones, compared to their positions following density equilibration, indicates $100 \mathrm{~ns}$ is sufficient to reach a local equilibrium (Additional file 1: Figure S10). Long-range electrostatic calculations used a non-bonded cutoff distance of $10 \AA$, a switching distance of $9 \AA$, and a non-bonded pair list distance of $12 \AA$. The SHAKE algorithm was used to fix the hydrogen distances during all simulations. For microfibril complexes, during heating, density equilibration and production simulation, the bottom layer of the cellulose crystal was harmonically restrained with a force constant of $1 \mathrm{kcal} / \mathrm{mol} / \AA^{2}$ to prevent twisting of the microfibril, which occurs when the degree of polymerization is low.

To initiate the high temperature simulations, we first conducted three independent 50-ns MD simulations of each apo enzyme ( 9 total simulations) at $300 \mathrm{~K}$ in the NVT ensemble using NAMD. The high temperature simulations were started from $10 \mathrm{~ns}, 300 \mathrm{~K}$ equilibrated snapshots of each enzyme. High-temperature simulations were conducted in NAMD at $475 \mathrm{~K}$ for $15 \mathrm{~ns}$ each; all other simulation parameters were as described above. Again, three independent simulations of each enzyme were performed to obtain statistically meaningful structural insight. VMD was used to visualize the trajectories of the high temperature simulations and define the thermally unstable regions of the enzymes. The native contact analysis described above was conducted in CHARMM using the COORdinate DMAT (distance matrix) command.

\section{Phylogenetic analysis}

GH7 protein sequences were retrieved by pBLAST search with the TreCel7A full-length sequence (UniProtKBP62694) in NCBI and individual species genome databases. Available sequences of both CBHs and EGs from Trichoderma spp., Fusarium spp. and C. rosea were selected, and one sequence from Acremonium strictum was included as an outgroup, resulting in a set of $28 \mathrm{GH} 7$ orthologs. The amino acid sequences were aligned by ClustalW using MEGA7 software [75], and regions flanking the GH7 domain were trimmed off (signal peptide, before Gln 1 of TatCel7A; linker-CBM, after Thr429 of TatCel7A). The evolutionary history was inferred using the minimum evolution method [76] and bootstrap phylogeny testing with 2000 replicates. The evolutionary distances were computed using the Dayhoff matrix based method [77] and are in the units of the number of amino acid substitutions per site. The minimum evolution tree was searched using the close-neighbor-interchange (CNI) algorithm [78] at a search level of 1 . The neighbor-joining algorithm [79] was used to generate the initial tree. All positions containing gaps and missing data were eliminated. There were a total of 349 positions in the final dataset.

\section{Reverse conservation analysis (RCA)}

A subset of $17 \mathrm{GH} 7 \mathrm{CBH}$ protein sequences, including 11 sequences from Trichoderma spp. and six sequences from Fusarium spp. and C. rosea, was selected. The GH7 $\mathrm{CBH}$ catalytic domains were realigned by ClustalW using MEGA7 software [75], followed by indel elimination. This alignment was analyzed by RCA as described earlier [35]. In short, Rate4Site (Version 2.01) was used to calculate the degree of conservation ( $S$ score) for each amino acid position using the empirical Bayesian method [80, 81]. A sliding window-average $(n=7) S$ score was plotted ( $W$ mean score) and significant peaks were defined by intensity $(I)$ values of 1 [35].

\section{Additional files}

Additional file 1: Figure S1. SDS-PAGE analyses of T. atroviride culture filtrate and purified Trichoderma spp. Cel7A enzymes. Figure S2. Substrate dependence plots and Hanes-Wolff plots from enzyme kinetics experiments with TatCel7A, ThaCel7A and TreCel7A, using pNP-Lac as substrate and cellobiose as inhibitor. Additional information regarding the mathematical model for quasi-steady state kinetics of processive cellulose hydrolysis by $\mathrm{GH} 7$ cellobiohydrolases and the derivation of kinetic parameters by non-linear regression fitting to real-time progress curves of the initial stage of cellulose hydrolysis. Figure S3. A) Real-time progress curves. B) Derivative of the progress curves in A). Figure S4. A) Simplified reaction scheme for a processive cellulase. B) Illustration of the molecular steps involved in the reaction scheme. Figure S5. Non-linear regression fit to real-time progress curves. Figure S6. Bar diagram of kinetic parameters derived from initial hydrolysis of BMCC. Additional information regarding correlation of kinetic parameters derived by non-linear regression fit to initial hydrolysis data. Table S1. Parameter correlation matrix for TreCel7A. Figure S7. Kinetic parameter fit to simulated data with $2.5 \%$ random noise added, and to experimental data recorded for TreCel7A during initial hydrolysis of BMCC. Table S2. Comparison of kinetic parameters from the fit to simulated data with $2.5 \%$ random noise, and to experimental data recorded for TreCel7A during initial hydrolysis of BMCC. Figure S8. Sequence alignment of the $\mathrm{GH} 7 \mathrm{CBH}$ catalytic domains used for RCA analysis. Figure S9. Phylogenetic tree of $\mathrm{GH} 7$ catalytic domain protein sequences from Trichoderma spp. and Fusarium spp. Table S3. S scores from RCA analysis for residues of interest for TatCel7A, ThaCel7A and TreCel7A. Additional MD simulation results Figure S10. RMSD as a function of time for each 100-ns, ligand-bound MD simulation of TatCel7A, ThaCel7A and TreCel7A catalytic domains.

Additional file 2: Movie S1. Movie of TatCel7A_CD initial protein unfolding during 15-ns MD simulations at high temperature (475 K). The movie shows three individual MD runs side-by-side for the same protein, in two views. The top row shows the "front" of the enzyme, and the bottom row shows the "backside".

Additional file 3: Movie S2. Movie of TreCel7A_CD initial protein unfolding during 15-ns MD simulations at high temperature (475 K). The movie shows three individual MD runs side-by-side for the same protein, in two views. The top row shows the "front" of the enzyme, and the bottom row shows the "backside".

Additional file 4: Movie S3. Movie of ThaCel7A_CD initial protein unfolding during 15-ns MD simulations at high temperature (475 K). The movie shows three individual MD runs side-by-side for the same protein, in two views. The top row shows the "front" of the enzyme, and the bottom row shows the "backside". 


\begin{abstract}
Abbreviations
BCA: biocontrol agent; BMCC: bacterial microcrystalline cellulose; $\mathrm{CBH}$ : cellobiohydrolase; CBM: carbohydrate binding module; CD: catalytic domain; EG: endo-1,4- $\beta$-D-glucanase; DP: degree of polymerization; GH6: glycoside hydrolase family 6; GH7: glycoside hydrolase family 7; MD: molecular dynamics; PCS: pretreated corn stover; $p$ NP-Lac: $p$-nitrophenyl $\beta$-lactoside; RCA: reverse conservation analysis; RMSD: root mean square deviation; RMSF: root mean square fluctuation; TatCel7A: Trichoderma atroviride Cel7A; ThaCel7A: Trichoderma harzianum Cel7A; TreCel7A: Trichoderma reesei Cel7A.
\end{abstract}

\section{Authors' contributions}

ASB and JS conceived and coordinated the study and wrote the paper. AAK initiated the study. EVE purified TatCel7A. ASB did fungal cultivation, purified and prepared TatCel7A, ThaCel7A, and TreCel7A, full-length and catalytic domains, and conducted biochemical characterization and processivity experiments. ASB crystallized TatCel7A_CD and determined X-ray structures. HH and MS conducted structure evaluation and deposition. SFB, ASB, JK, and PW conducted BMCC hydrolysis experiments, data analysis, and interpretation. AA and $\mathrm{MEH}$ analyzed enzyme performance on PCS. ASB, HH, and MK conducted phylogenetic analysis and RCA analysis. SJ and CMP performed MD simulations and results interpretation. CMP and MEH proof read the manuscript. All authors read and approved the final manuscript.

\begin{abstract}
Author details
${ }^{1}$ Department of Molecular Sciences, Swedish University of Agricultural Sciences, P.O. Box 7015, 75007 Uppsala, Sweden. ${ }^{2}$ B.P. Konstantinov Petersburg Nuclear Physics Institute, National Research Centre "Kurchatov Institute", Orlova Roscha, Gatchina, Leningrad Region 188300, Russia. ${ }^{3}$ Department of Chemical and Materials Engineering, University of Kentucky, 177 F. Paul Anderson Tower, Lexington, KY 40506-0046, USA. ${ }^{4}$ Department of Science and Environment, Roskilde University, 1 Universitetsvej, 4000 Roskilde, Denmark. ${ }^{5}$ National Renewable Energy Laboratory, Biosciences Center, 15013 Denver West Parkway, Golden, CO 80401, USA. ${ }^{6}$ Department of Forest Mycology and Plant Pathology, Swedish University of Agricultural Sciences, P.O. Box 7026, 75007 Uppsala, Sweden. ${ }^{7}$ Department of Medical Physics, Peter the Great St. Petersburg Polytechnic University, Saint Petersburg, Russia. ${ }^{8}$ Present Address: Division of Chemical, Bioengineering, Environmental, and Transport Systems, National Science Foundation, Alexandria, VA, USA.
\end{abstract}

\section{Acknowledgements}

We acknowledge Farid Ibatullin for the synthesis of thio-linked cellotriose used in crystallization experiments.

\section{Competing interests}

The authors declare that they have no competing interests.

\section{Availability of data and materials}

The protein structure models and structure factors are available in the Protein Data Bank (http://wwpdb.org/) under accession codes 5O5D and 5059. All other data generated and/or analyzed during the current study are either included in this published article and its Additional files, or available in public databases (e.g. Embank, Uniprot, JGI MycoCosm portal), or available from the corresponding author on reasonable request.

\section{Consent for publication}

Not applicable.

\section{Ethics approval and consent to participate}

Not applicable.

\section{Funding}

This material is based upon work supported by the Swedish Research Council for Environment, Agricultural Sciences and Spatial Planning (Formas; Grant Number 213-2013-1607; PI: JS); Russian Science Foundation (Grant Number 16-14-00109; PI: AAK); the National Science Foundation (NSF) under Grant Number 1552355 (former Pl: CMP); Novo Nordisk Foundation (Grant Number NNF15OC0016606; PI: PW) and Innovation Fund Denmark (Grant Number 5150-00020B; PI: PW). This material is also based upon work supported by (while CMP is serving at) the NSF. Any opinion, findings, and conclusions or recommendations expressed in this material are those of the authors and do not necessarily reflect the views of the NSF. Computing resources for MD simulations were provided by the University of Kentucky and NSF Extreme Science and Engineering Discovery Environment (XSEDE), which is supported by NSF Grant Number ACl-1548562.

\section{Publisher's Note}

Springer Nature remains neutral with regard to jurisdictional claims in published maps and institutional affiliations.

Received: 5 October 2017 Accepted: 23 December 2017

Published online: 13 January 2018

\section{References}

1. Martinez D, Berka RM, Henrissat B, Saloheimo M, Arvas M, Baker SE, Chapman J, Chertkov O, Coutinho PM, Cullen D, et al. Genome sequencing and analysis of the biomass-degrading fungus Trichoderma reesei (syn. Hypocrea jecorina). Nat Biotechnol. 2008;26:553-60.

2. Bischof RH, Ramoni J, Seiboth B. Cellulases and beyond: the first 70 years of the enzyme producer Trichoderma reesei. Microb Cell Fact. 2016;15:106.

3. Borisova AS, Eneyskaya EV, Bobrov KS, Jana S, Logachev A, Polev DE, Lapidus AL, Ibatullin FM, Saleem U, Sandgren M, et al. Sequencing, biochemical characterization, crystal structure and molecular dynamics of cellobiohydrolase Cel7A from Geotrichum candidum 3C. FEBS J. 2015;282:4515-37.

4. Knott BC, Crowley MF, Himmel ME, Stahlberg J, Beckham GT. Carbohydrate-protein interactions that drive processive polysaccharide translocation in enzymes revealed from a computational study of cellobiohydrolase processivity. J Am Chem Soc. 2014;136:8810-9.

5. Momeni MH, Goedegebuur F, Hansson H, Karkehabadi S, Askarieh G, Mitchinson C, Larenas EA, Stahlberg J, Sandgren M. Expression, crystal structure and cellulase activity of the thermostable cellobiohydrolase Cel7A from the fungus Humicola grisea var. thermoidea. Acta Crystallogr D Biol Crystallogr. 2014;70:2356-66.

6. Momeni MH, Ubhayasekera W, Sandgren M, Stahlberg J, Hansson H. Structural insights into the inhibition of cellobiohydrolase Cel7A by xylooligosaccharides. FEBS J. 2015;282:2167-77.

7. Payne CM, Knott BC, Mayes HB, Hansson H, Himmel ME, Sandgren M, Stahlberg J, Beckham GT. Fungal cellulases. Chem Rev. 2015;115:1308-448.

8. Sorensen TH, WindahI MS, McBrayer B, Kari J, Olsen JP, Borch K, Westh P. Loop variants of the thermophile Rasamsonia emersonii Cel7A with improved activity against cellulose. Biotechnol Bioeng. 2017;114:53-62.

9. Voutilainen SP, Murray PG, Tuohy MG, Koivula A. Expression of Talaromyces emersonii cellobiohydrolase Cel7A in Saccharomyces cerevisiae and rational mutagenesis to improve its thermostability and activity. Protein Eng Des Sel. 2010;23:69-79.

10. Cherry JR, Fidantsef AL. Directed evolution of industrial enzymes: an update. Curr Opin Biotechnol. 2003;14:438-43.

11. Gritzali MB, Jr RD. The cellulase system of Trichoderma: relationship between purified extracellular enzymes from induced or cellulose-grown cells. Adv Chem Ser. 1979;181:237-60.

12. Beckham GT, Bomble YJ, Matthews JF, Taylor CB, Resch MG, Yarbrough JM, Decker SR, Bu L, Zhao X, McCabe C, et al. The O-glycosylated linker from the Trichoderma reesei family 7 cellulase is a flexible, disordered protein. Biophys J. 2010;99:3773-81.

13. Sammond DW, Payne CM, Brunecky R, Himmel ME, Crowley MF, Beckham GT. Cellulase linkers are optimized based on domain type and function: insights from sequence analysis, biophysical measurements, and molecular simulation. PLoS ONE. 2012;7:e48615.

14. Stals I, Sandra K, Geysens S, Contreras R, Van Beeumen J, Claeyssens M. Factors influencing glycosylation of Trichoderma reesei cellulases. I: postsecretorial changes of the $\mathrm{O}$ - and $\mathrm{N}$-glycosylation pattern of Cel7A. Glycobiology. 2004;14:713-24.

15. Divne C, Ståhlberg J, Reinikainen T, Ruohonen L, Pettersson G, Knowles $\mathrm{JK}$, Teeri TT, Jones TA. The three-dimensional crystal structure of the catalytic core of cellobiohydrolase I from Trichoderma reesei. Science. 1994;265:524-8. 
16. Kraulis J, Clore GM, Nilges M, Jones TA, Pettersson G, Knowles J, Gronenborn AM. Determination of the three-dimensional solution structure of the C-terminal domain of cellobiohydrolase I from Trichoderma reesei. A study using nuclear magnetic resonance and hybrid distance geometrydynamical simulated annealing. Biochemistry. 1989;28:7241-57.

17. Kurasin M, Valjamae P. Processivity of cellobiohydrolases is limited by the substrate. J Biol Chem. 2011;286:169-77.

18. Hobdey SE, Knott BC, Haddad Momeni M, Taylor LE 2nd, Borisova AS, Podkaminer KK, VanderWall TA, Himmel ME, Decker SR, Beckham GT, et al. Biochemical and structural characterizations of two dictyostelium cellobiohydrolases from the amoebozoa kingdom reveal a high level of conservation between distant phylogenetic trees of life. Appl Environ Microbiol. 2016:82:3395-409.

19. King AJ, Cragg SM, Li Y, Dymond J, Guille MJ, Bowles DJ, Bruce NC, Graham IA, McQueen-Mason SJ. Molecular insight into lignocellulose digestion by a marine isopod in the absence of gut microbes. Proc Natl Acad Sci USA. 2010;107:5345-50.

20. Momeni MH, Payne CM, Hansson H, Mikkelsen NE, Svedberg J, Engström Å, Sandgren M, Beckham GT, Ståhlberg J. Structural, biochemical, and computational characterization of the glycoside hydrolase family 7 cellobiohydrolase of the tree-killing fungus Heterobasidion irregulare. J Biol Chem. 2013;288:5861-72

21. Textor LC, Colussi F, Silveira RL, Serpa V, de Mello BL, Muniz JR, Squina FM, Pereira N Jr, Skaf MS, Polikarpov I. Joint X-ray crystallographic and molecular dynamics study of cellobiohydrolase I from Trichoderma harzianum: deciphering the structural features of cellobiohydrolase catalytic activity. FEBS J. 2013;280:56-69.

22. Grigorevski-Lima AL, de Oliveira MM, do Nascimento RP, Bon EP, Coelho RR. Production and partial characterization of cellulases and xylanases from Trichoderma atroviride 676 using lignocellulosic residual biomass. Appl Biochem Biotechnol. 2013;169:1373-85

23. Jiang X, Geng A, He N, Li Q. New isolate of Trichoderma viride strain for enhanced cellulolytic enzyme complex production. J Biosci Bioeng. 2011;111:121-7

24. Kovacs K, Szakacs G, Zacchi G. Comparative enzymatic hydrolysis of pretreated spruce by supernatants, whole fermentation broths and washed mycelia of Trichoderma reesei and Trichoderma atroviride. Bioresour Technol. 2009;100:1350-7.

25. van Wyk JP, Mohulatsi M. Biodegradation of wastepaper by cellulase from Trichoderma viride. Bioresour Technol. 2003;86:21-3.

26. Karlsson M, Atanasova L, Jensen D, Zeilinger S. Necrotrophic mycoparasites and their genomes. In: Heitman J, Howlett B, Crous P, Stukenbrock E, James T, Gow N, editors. The fungal kingdom. Washington, DC: ASM Press; 2017. p. 1005-1026. https://doi.org/10.1128/microbiolspec. FUNK-0016-2016.

27. Schmoll M, Dattenbock C, Carreras-Villasenor N, Mendoza-Mendoza A, Tisch D, Aleman MI, Baker SE, Brown C, Cervantes-Badillo MG, Cetz-Chel J, et al. The genomes of three uneven siblings: footprints of the lifestyles of three Trichoderma species. Microbiol Mol Biol Rev. 2016;80:205-327.

28. Druzhinina IS, Seidl-Seiboth V, Herrera-Estrella A, Horwitz BA, Kenerley CM, Monte E, Mukherjee PK, Zeilinger S, Grigoriev IV, Kubicek CP. Trichoderma: the genomics of opportunistic success. Nat Rev Microbiol. 2011;9:749-59.

29. Liu M, Sun ZX, Zhu J, Xu T, Harman GE, Lorito M. Enhancing rice resistance to fungal pathogens by transformation with cell wall degrading enzyme genes from Trichoderma atroviride. J Zhejiang Univ Sci. 2004;5:133-6.

30. de Castro AM, Pedro KC, da Cruz JC, Ferreira MC, Leite SG, Pereira N Jr. Trichoderma harzianum IOC-4038: a promising strain for the production of a cellulolytic complex with significant beta-glucosidase activity from sugarcane bagasse cellulignin. Appl Biochem Biotechnol. 2010;162:2111-22.

31. Ståhlberg J, Divne C, Koivula A, Piens K, Claeyssens M, Teeri TT, Jones TA. Activity studies and crystal structures of catalytically deficient mutants of cellobiohydrolase I from Trichoderma reesei. J Mol Biol. 1996;264:337-49.

32. Cruys-Bagger N, Ren G, Tatsumi H, Baumann MJ, Spodsberg N, Andersen HD, Gorton L, Borch K, Westh P. An amperometric enzyme biosensor for real-time measurements of cellobiohydrolase activity on insoluble cellulose. Biotechnol Bioeng. 2012;109:3199-204.

33. Cruys-Bagger N, Tatsumi H, Ren GR, Borch K, Westh P. Transient kinetics and rate-limiting steps for the processive cellobiohydrolase Cel7A: effects of substrate structure and carbohydrate binding domain. Biochemistry. 2013;52:8938-48.
34. Praestgaard E, Elmerdahl J, Murphy L, Nymand S, McFarland KC, Borch K, Westh P. A kinetic model for the burst phase of processive cellulases. FEBS J. 2011;278:1547-60.

35. Lee TS. Reverse conservation analysis reveals the specificity determining residues of cytochrome P450 family 2 (CYP 2). Evol Bioinform Online. 2008:4:7-16.

36. Cole MF, Gaucher EA. Utilizing natural diversity to evolve protein function: applications towards thermostability. Curr Opin Chem Biol. 2011;15:399-406.

37. Jalak J, Kurašin M, Teugjas H, Väljamäe P. Endo-exo synergism in cellulose hydrolysis revisited. J Biol Chem. 2012;287:28802-15.

38. Kont R, Kari J, Borch K, Westh P, Väljamäe P. Inter-domain synergism is required for efficient feeding of cellulose chain into active site of cellobiohydrolase Cel7A. J Biol Chem. 2016;291:26013-23.

39. von Ossowski I, Ståhlberg J, Koivula A, Piens K, Becker D, Boer H, Harle R, Harris M, Divne C, Mahdi S, et al. Engineering the exo-loop of Trichoderma reesei cellobiohydrolase, Cel7A. A comparison with Phanerochaete chrysosporium Cel7D. J Mol Biol. 2003;333:817-29.

40. Wohlfahrt G, Pellikka T, Boer H, Teeri TT, Koivula A. Probing pHdependent functional elements in proteins: modification of carboxylic acid pairs in Trichoderma reesei cellobiohydrolase Cel6A. Biochemistry. 2003:42:10095-103.

41. Goedegebuur F, Dankmeyer L, Gualfetti P, Karkehabadi S, Hansson H, Jana S, Huynh V, Kelemen BR, Kruithof P, Larenas EA, Teunissen PJM, Ståhlberg J, Payne CM, Mitchinson C, Sandgren M. Improving the thermal stability of cellobiohydrolase Cel7A from Hypocrea jecorina by directed evolution. J Biol Chem. 2017;292:17418-30.

42. Srisodsuk M, Reinikainen T, Penttila M, Teeri TT. Role of the interdomain linker peptide of Trichoderma reesei cellobiohydrolase I in its interaction with crystalline cellulose. J Biol Chem. 1993;268:20756-61.

43. Klarskov K, Piens K, Stahlberg J, Hoj PB, Beeumen JV, Claeyssens M. Cellobiohydrolase I from Trichoderma reesei: identification of an active-site nucleophile and additional information on sequence including the glycosylation pattern of the core protein. Carbohydr Res. 1997;304:143-54.

44. Linger JG, Taylor LE 2nd, Baker JO, Vander Wall T, Hobdey SE, Podkaminer K, Himmel ME, Decker SR. A constitutive expression system for glycosyl hydrolase family 7 cellobiohydrolases in Hypocrea jecorina. Biotechnol Biofuels. 2015:8:45.

45. Valjamae P, Sild V, Nutt A, Pettersson G, Johansson G. Acid hydrolysis of bacterial cellulose reveals different modes of synergistic action between cellobiohydrolase I and endoglucanase I. Eur J Biochem. 1999;266:327-34.

46. Cruys-Bagger N, Elmerdahl J, Praestgaard E, Tatsumi H, Spodsberg N, Borch K, Westh P. Pre-steady-state kinetics for hydrolysis of insoluble cellulose by cellobiohydrolase Cel7A. J Biol Chem. 2012;287:18451-8.

47. Chen X, Wang W, Ciesielski P, Trass O, Park S, Tao L, Tucker MP. Improving sugar yields and reducing enzyme loadings in the deacetylation and mechanical refining (DMR) process through multistage disk and Szego refining and corresponding techno-economic analysis. ACS Sustain Chem Eng. 2016:4:324-33.

48. Chen X, Kuhn E, Wang W, Park S, Flanegan K, Trass O, Tenlep L, Tao L, Tucker M. Comparison of different mechanical refining technologies on the enzymatic digestibility of low severity acid pretreated corn stover. Bioresour Technol. 2013;147:401-8.

49. Baker JO, Ehrman C I, Adney WS, Thomas SR, Himmel ME. Hydrolysis of cellulose using ternary mixtures of purified cellulases. In: Biotechnology for fuels and chemicals: proceedings of the nineteenth symposium on biotechnology for fuels and chemicals held May 4-8, 1997, at Colorado Springs, Colorado (Finkelstein M, Davison BH, editors), Humana Press, Totowa, NJ. 1998. p. 395-403.

50. Resch MG, Baker JO, Decker SR. Low solids enzymatic saccharification of lignocellulosic biomass. Laboratory analytical procedure (LAP). NREL Technical report, 2015. NREL/TP-5100-63351. 2015. https://www.nrel.gov/ publications.

51. Kabsch W, Sander C. Dictionary of protein secondary structure: pattern recognition of hydrogen-bonded and geometrical features. Biopolymers. 1983:22:2577-637.

52. Evans PR. An introduction to data reduction: space-group determination, scaling and intensity statistics. Acta Crystallogr D Biol Crystallogr. 2011;67:282-92.

53. McCoy AJ, Grosse-Kunstleve RW, Adams PD, Winn MD, Storoni LC, Read RJ. Phaser crystallographic software. J Appl Crystallogr. 2007;40:658-74. 
54. Murshudov GN, Skubak P, Lebedev AA, Pannu NS, Steiner RA, Nicholls RA, Winn MD, Long F, Vagin AA. REFMAC5 for the refinement of macromolecular crystal structures. Acta Crystallogr D Biol Crystallogr. 2011:67:355-67.

55. Emsley P, Cowtan K. Coot: model-building tools for molecular graphics. Acta Crystallogr D Biol Crystallogr. 2004;60:2126-32.

56. Emsley P, Lohkamp B, Scott WG, Cowtan K. Features and development of Coot. Acta Crystallogr D Biol Crystallogr. 2010;66:486-501.

57. Collaborative Computational Project. The CCP4 suite: programs for protein crystallography. Acta Crystallogr D Biol Crystallogr. 1994;50:760-3.

58. Langer G, Cohen SX, Lamzin VS, Perrakis A. Automated macromolecular model building for $X$-ray crystallography using ARP/wARP version 7. Nat Protoc. 2008;3:1171-9.

59. Knott BC, Momeni MH, Crowley MF, Mackenzie LF, Gotz AW, Sandgren M, Withers SG, Ståhlberg J, Beckham GT. The mechanism of cellulose hydrolysis by a two-step, retaining cellobiohydrolase elucidated by structural and transition path sampling studies. J Am Chem Soc. 2014;136:321-9.

60. Schrödinger L. The PyMOL molecular graphics system 1.5.0.4. 2010.

61. Taylor CB, Payne CM, Himmel ME, Crowley MF, McCabe C, Beckham GT. Binding site dynamics and aromatic-carbohydrate interactions in processive and non-processive family 7 glycoside hydrolases. J Phys Chem B. 2013;117:4924-33.

62. Anandakrishnan R, Aguilar B, Onufriev AV. H++3.0: automating pK prediction and the preparation of biomolecular structures for atomistic molecular modeling and simulations. Nucleic Acids Res. 2012:40:W537-41.

63. Gordon JC, Myers JB, Folta T, Shoja V, Heath LS, Onufriev A. H++: a server for estimating $\mathrm{pK}(\mathrm{a}) \mathrm{s}$ and adding missing hydrogens to macromolecules. Nucleic Acids Res. 2005;33:W368-71.

64. Myers J, Grothaus G, Narayanan S, Onufriev A. A simple clustering algorithm can be accurate enough for use in calculations of pKs in macromolecules. Proteins Struct Funct Genet. 2006;63:928-38.

65. Brooks BR, Brooks CL, Mackerell AD, Nilsson L, Petrella RJ, Roux B, Won Y, Archontis G, Bartels C, Boresch S, et al. CHARMM: the biomolecular simulation program. J Comput Chem. 2009;30:1545-614.

66. Hunenberger PH, McCammon JA. Ewald artifacts in computer simulations of ionic solvation and ion-ion interaction: a continuum electrostatics study. J Chem Phys. 1999;1 10:1856-72.

67. Figueirido F, Delbuono GS, Levy RM. On finite-size effects in computersimulations using the Ewald potential. J Chem Phys. 1995;103:6133-42.

68. MacKerell AD, Bashford D, Bellott M, Dunbrack RL, Evanseck JD, Field MJ, Fischer S, Gao J, Guo H, Ha S, et al. All-atom empirical potential for molecular modeling and dynamics studies of proteins. J Phys Chem B. 1998:102:3586-616.
69. Mackerell AD, Feig M, Brooks CL. Extending the treatment of backbone energetics in protein force fields: limitations of gas-phase quantum mechanics in reproducing protein conformational distributions in molecular dynamics simulations. J Comput Chem. 2004;25:1400-15.

70. Guvench O, Greene SN, Kamath G, Brady JW, Venable RM, Pastor RW, Mackerell AD. Additive empirical force field for hexopyranose monosaccharides. J Comput Chem. 2008:29:2543-64.

71. Guvench O, Hatcher E, Venable RM, Pastor RW, Mackerell AD. CHARMM additive all-atom force field for glycosidic linkages between hexopyranoses. J Chem Theory Comput. 2009;5:2353-70.

72. Jørgensen WL, Chandrasekhar J, Madura JD, Impey RW, Klein ML. Comparison of simple potential functions for simulating liquid water. J Chem Phys. 1983;79:926-35.

73. Durell SR, Brooks BR, Bennaim A. Solvent-induced forces between 2 hydrophilic groups. J Phys Chem. 1994;98:2198-202.

74. Phillips JC, Braun R, Wang W, Gumbart J, Tajkhorshid E, Villa E, Chipot C, Skeel RD, Kale L, Schulten K. Scalable molecular dynamics with NAMD. J Comput Chem. 2005:26:1781-802.

75. Kumar S, Stecher G, Tamura K. MEGA7: molecular evolutionary genetics analysis version 7.0 for bigger datasets. Mol Biol Evol. 2016:33:1870-4.

76. Rzhetsky A, Nei M. Statistical properties of the ordinary least-squares, generalized least-squares, and minimum-evolution methods of phylogenetic inference. J Mol Evol. 1992;35:367-75.

77. Schwartz RDM. Matrices for detecting distant relationships. Atlas Protein Seq Struct. 1978;5:353-8.

78. Nei M, Kumar S. Molecular evolution and phylogenetics. Oxford: Oxford University Press; 2000

79. Saitou NNM. The neighbor-joining method: a new method for reconstructing phylogenetic trees. Mol Biol Evol. 1987;4:406-25.

80. Mayrose I, Graur D, Ben-Tal N, Pupko T. Comparison of site-specific rateinference methods for protein sequences: empirical Bayesian methods are superior. Mol Biol Evol. 2004;21:1781-91.

81. Pupko T, Bell RE, Mayrose I, Glaser F, Ben-Tal N. Rate4Site: an algorithmic tool for the identification of functional regions in proteins by surface mapping of evolutionary determinants within their homologues. Bioinformatics. 2002;18(Suppl 1):S71-7.

82. Robert $X$, Gouet P. Deciphering key features in protein structures with the new ENDscript server. Nucleic Acids Res. 2014;42:W320-4.

\section{Submit your next manuscript to BioMed Central and we will help you at every step:}

- We accept pre-submission inquiries

- Our selector tool helps you to find the most relevant journal

- We provide round the clock customer support

- Convenient online submission

- Thorough peer review

- Inclusion in PubMed and all major indexing services

- Maximum visibility for your research

Submit your manuscript at www.biomedcentral.com/submit
BioMed Central 